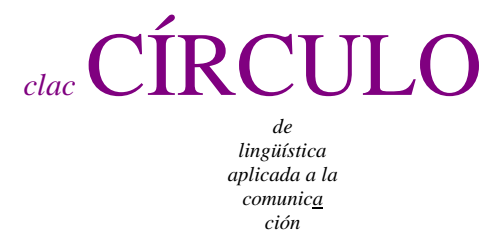

$58 / 2014$

\title{
¿PARA QUÉ SIRVE ARGUMENTAR?: PROBLEMATIZANDO TEÓRICA Y \\ EMPÍRICAMENTE EL VALOR Y LA FUNCIÓN DE LA ARGUMENTACIÓN
}

\author{
Cristián Santibáñez \\ Universidad Diego Portales \\ cristian.santibanez en upd cl
}

\section{Resumen}

Este trabajo tiene dos objetivos principales. Primero, discutir algunos alcances conceptuales sobre el valor y la función de la actividad argumentativa a partir de varias posiciones críticas a la visión estándar de la teoría de la argumentación sobre estos tópicos; y en segundo lugar, presentar y discutir los resultados de una investigación empírica en torno al valor y función que jóvenes universitarios chilenos le dan a la actividad de argumentar con el propósito de ofrecer información ecológica que sirva para refutar o corroborar la discusión de carácter conceptual.

Palabras clave: cognición, ecología argumentativa, razonamiento, teoría de la argumentación.

Santibáñez, Cristián. 2014.

¿Para qué sirve argumentar?: Problematizando teórica y empíricamente el valor y la función de la argumentación.

Círculo de Lingüística Aplicada a la Comunicación 58, 163-205.

http://www.ucm.es/info/circulo/no58/santibanez.pdf

http://revistas.ucm.es/index.php/CLAC

http://dx.doi.org/10.5209/rev_CLAC.2014.v58.45474

(C)2014 Cristián Santibañez

Círculo de Lingüística Aplicada a la Comunicación (clac)

Universidad Complutense de Madrid. ISSN 1576-4737. http://www.ucm.es/info/circulo 


\begin{abstract}
What is the use of argumentation? Discussing theoretically and empirically the value and the function of argumentation.This paper has two main goals. First, discussing some conceptual issues about the value and function of the argumentative practice taking into consideration some critical position to the standard perspective on the matter; and second, presenting and discussing the result of an empirical research about the value and function that young colleges students give to the argumentative activity in order to offer ecological information that allows to refuse or corroborate the conceptual discussion.
\end{abstract}

Keywords: argumentative ecology, argumentation theory, cognition, reasoning.

Índice

TResumen 163

Abstract 164

1. Introducción 165

2. Antecedentes generales sobre valoración y funcionalidad de la argumentación 167

2.1. Funcionalidad-instrumentalidad argumentativa 167

2.2. Funcionalidad y valor de la práctica argumentativa en la teoría estándar 171

2.3. Críticas a la funcionalidad positiva (o bondadosa) de la argumentación desde la psicología del razonamiento 173

2.4. La funcionalidad argumentativa como problema comunicativo 175

3. Estudios Empíricos 179

3.1. Ecología argumentativa en Chile. Valor y función en jóvenes universitarios 181

3.1.1. Marco metodológico 182

4. Principales resultados y discusión 184

5. Conclusiones 191

Bibliografía 192

Anexo 198 


\section{Introducción}

Lo que intuitivamente parece una obviedad, a saber, que argumentar tiene una(s) función(es) natural(es) a partir de la(s) que brotaría cierto tipo de normatividad, no queda tan claro a partir de una reciente discusión en el seno de la teoría de la argumentación ${ }^{1}$. Goodwin (2007) en Informal Logic, quizá la principal revista del área, publicó un artículo cuyo estimulante y desafiante título fue Arguments Has No Functions, que fue luego rebatido por Patterson (2011) en cada una de sus partes. Entre otros temas que esta discusión puso de relieve, destacan con claridad dos: 1) los supuestos que la teoría de la argumentación utiliza, entre ellos: a) que habría un acuerdo tácito entre los interlocutores de llevar a cabo un diálogo argumentativo, es decir, operaría una dimensión dialéctica por defecto, y b) que argumentar tendría por objetivo resolver un problema, es decir, operaría un fenómeno pragmático en tanto co-sustancial a la actividad argumentativa; y 2) que a partir de tales supuestos (acuerdo intersubjetivo implícito de desarrollar dialécticamente un diálogo argumentativo, y que éste produzca un bien social -la resolución de un conflicto-), se obtenga los márgenes normativos de esta actividad.

El problema de la normatividad, esto es, bajo qué parámetros se lleva a cabo una buena argumentación, es sine qua non a la argumentación, la actividad misma la presupone. Cuando un agente argumenta en la vida diaria, lo hace considerando, explícita o implícitamente, que su argumento es el mejor, el más fuerte, el más adecuado, u otros adjetivos de bondad que pudieran usarse según un contexto lo determine, pues de lo contrario se auto-derrotaría, o tendría algún grado de inadecuación lógica y pragmática.

1 Este trabajo es parte de los resultados del proyecto titulado "Valor, función y complejidad argumentativa en estudiantes universitarios: el caso en las regiones de Coquimbo y Metropolitana” subvencionado por el Fondo Nacional de Desarrollo Científico y Tecnológico de Chile, proyecto No. 1130584. 
La teoría de la argumentación ha reflejado este hecho básico. Hemos presenciado un desarrollo sistemático en torno a un procedimiento de resolución de diferencias de opinión en virtud de comandos para la buena argumentación (van Eemeren y Grootendorst, [1992] 2002, 2004; van Eemeren, 2010); criterios esenciales para la producción de buenos argumentos (Johnson, 2000); la explicación de la normatividad local dependiendo de los tipos de diálogos y el uso de preguntas críticas (Walton y Krabbe, 1995; Walton, Reed y Macgano, 2008).

Para satisfacer los alcances teóricos de las distintas posiciones, se ha intentado recientemente cerrar la brecha empírica testeando los parámetros normativos que hablantes naturales utilizan cuando argumentan; así lo ha hecho la pragma-dialéctica (van Eemeren, Garssen y Meuffels, 2009), aunque para algunos no del todo satisfactoriamente (de Angelis, 2012, Zenker, 2011).

Ciertamente sería un despropósito obviar la producción en otras áreas afines a la teoría de la argumentación que sí ha contribuido en el análisis del valor y la función que las personas en contextos naturales (o semi naturales) le dan a la actividad argumentativa (Hample, 2004, 2005), y desde la que se podría abstraer normatividad. ${ }^{2}$

En este contexto, el presente artículo tiene por objetivos específicos: a) discutir el estado del arte en relación con el problema de la valoración y funcionalidad de la argumentación para efectos de postular normatividad argumentativa; b) hacer converger literatura de distintas disciplinas y áreas que trabajan en los mismos problemas y que muchas veces no se disponen en cruzamientos que favorezcan nuevos avances; y c) dar cuenta de los resultados preliminares de una investigación empírica que busca caracterizar el valor y función que jóvenes estudiantes universitarios de Chile le dan a la actividad argumentativa.

\footnotetext{
${ }^{2}$ Se señala semi-naturales porque las investigaciones reportan resultados a partir de la utilización de métodos como las encuestas, las entrevistas, los grupos de discusión que, evidentemente, no reemplazan al contexto natural donde no media un experto, como es el investigador y/o encuestador.
} 
2. Antecedentes generales sobre valoración y funcionalidad de la argumentación ${ }^{3}$

\subsection{Funcionalidad-instrumentalidad argumentativa}

De acuerdo con Paglieri y Castelfranchi (2010; en adelante P\&C), la frecuente reticencia a argumentar tiene una función estratégica, ya que no participamos en una discusión cuando hay probabilidad de terminar con un resultado negativo. Para los autores, argumentar es una actividad demandante y no se emprende sin un propósito y una debida consideración; se suele evaluar los costos, beneficios y peligros para decidir si vale la pena argumentar. Según $\mathrm{P} \& C$, las teorías argumentativas suelen hacer dos suposiciones cruciales: que fallar en la actividad argumentativa deja a los argumentadores en la misma situación respecto de la que comenzaron, por lo que no habría mayor problema en fallar, y que las metas dialógicas son las principales preocupaciones de los argumentadores cuando deciden involucrarse en una argumentación. Se asume, de acuerdo con P\&C, que las características estándares que la argumentación intenta mejorar incluyen: credibilidad de una conclusión, el nivel de acuerdo entre las partes, el estado emocional y las relaciones sociales de los argumentadores, la ventaja estratégica de cada argumentador en el contexto de una disputa y la reputación social del argumentador como una fuente fidedigna de información. En las teorías de la argumentación se suele creer que la argumentación solo puede hacer las cosas mejores. Esto es lo que P\&C denominan optimismo argumentativo. Sin embargo, la argumentación puede (y muchas veces suele) producir resultados negativos. Hay muchas formas en que la situación puede empeorar, por ejemplo: los malos argumentos suelen ser contraproducentes (dañan la credibilidad final de la conclusión); puede ocurrir una escalada produciendo un aumento del desacuerdo; los argumentos sobre temas emocionales generan una serie de sentimientos provocando

\footnotetext{
${ }^{3}$ Agradezco el aporte a esta sección hecho por las asistentes de investigación Antonia García y Fernanda Aeschlimann.
} 
que ambas partes sufran pérdidas emocionales sin que se obtenga beneficio alguno; un argumento imprudente lleva la atención de la contraparte a temas que aumentan la fuerza de su oposición y disminuyen la propia; y una derrota argumentativa puede tener una consecuencia negativa en la reputación del perdedor. Además de ser falso, el optimismo argumentativo impide el análisis de costos y beneficios, que es lo que vienen a sostener P\&C como la lectura instrumental o funcional correcta de la práctica argumentativa.

Cuando se habla de instrumentalismo argumentativo, se quiere decir que las metas dialógicas suelen ser de carácter instrumental a la meta extra- dialógica. Un ejemplo explica esta visión de forma directa: si un vendedor de auto te dice en el diálogo que el auto que observan fue elegido como el más económico, no está sólo aseverando algo sobre el auto, pues obviamente su meta extra-dialógica es venderte el auto. Esto implica que la decisión de argumentar, y las decisiones respecto de los movimientos específicos en el proceso mismo, es afectada por las metas extradialógicas del argumentador. El instrumentalismo argumentativo tiene tres características: 1) las sub-metas dialógicas son instrumentales al fin del diálogo (alabar el diseño del auto para convencer al comprador), que a la vez es instrumental a la meta extra-dialógica (vender el auto); 2) la meta extra-dialógica tiene superioridad sobre el diálogo inmediato; 3) algunos movimientos pueden ser instrumentales a otras metas extra-dialógicas del argumentador, diferentes de aquellas que motivaron al argumentador en primera instancia (el vendedor intenta impresionar a una chica que observa la venta). Para P\&C, aceptar estas ideas es importante para el desarrollo del análisis de costos y beneficios de la argumentación, ya que los beneficios y peligros de argumentar solo pueden ser evaluados en relación con las metas extra dialógicas que nos instan a participar en una actividad como ésta.

La manera más directa de definir beneficio, costo y peligro es en términos de utilidad. Los beneficios son obtienen con el cumplimiento de las metas (ya sean dialógicas como extra dialógicas) del agente a través del acto argumentativo: convencer respecto de una creencia, lograr que el oyente oriente su acción de acuerdo a una creencia esgrimida, etc.; pero también cualquier efecto colateral positivo, como por ejemplo: reputación, confiabilidad, credibilidad, etc. En cambio, la utilidad negativa se divide en dos: costos y peligros. Cuando se habla de costos, se refiere a la utilidad 
negativa producida en el proceso de argumentar en virtud del balance entre el costo energético del agente y las metas, sin tomar en cuenta el producto. Esto incluye el costo directo y el costo de oportunidad, es decir, aquellas opciones no elegidas. En cambio, peligro se refiere a la utilidad negativa producida por efectos colaterales o como consecuencia de argumentar.

Para P\&C, todas estas consideraciones de toma de decisiones estratégicas se cruzan con el filtro de las expectativas del agente, por eso deben ser consideradas a priori (utilidad esperada). No hay razón para asumir que el argumentador calcula esta utilidad esperada a la vez que toma en consideración todos los factores que la afectan. De modo que, se preguntan los autores, ¿cuáles son los beneficios de argumentar? Se responden que en la medida en que la meta dialógica es instrumental a la meta extra dialógica, hay al menos dos posibilidades que modulan la utilidad esperada del agente: la probabilidad de que la argumentación pueda alcanzar su meta dialógica, y la probabilidad de que al ocurrir esto se produzca la satisfacción de la meta final extra dialógica. Estas probabilidades suelen diferir. A partir de esta combinación surge la tercera probabilidad, la que realmente le importa al argumentador: la probabilidad de satisfacer la meta extra dialógica que motiva toda la empresa argumentativa (alabar el auto $=$ convencer de que ese auto vale la pena $=$ compra del auto $=$ impresionar $\mathrm{a}$ alguien con la capacidad de vender). Un elemento clave es la calidad de las alternativas, esto es, otros argumentos a través de los cuales se puede lograr la meta extra dialógica del agente. La presencia o ausencia de alternativas, además de su cualidad, son elementos que se sopesan y se comparan.

¿Cuáles son los costos entonces? Según P\&C, hemos olvidado que la actividad argumentativa implica sufrir costos directos, como energía, recursos cognitivos, exposición social, etc. Estos aumentan según la duración de la argumentación. Por otro lado, no pasa lo mismo con los beneficios de argumentar, ya que éstos varían en relación con el tipo de argumentación que se lleve a cabo. En algunos casos los beneficios aumentan al incrementarse la duración de la discusión, y en otros la duración de ésta no es relevante para alcanzar la meta propuesta. En este sentido, en distintos tipos de argumentación, como la persuasión o la negociación, los costos aumentan cuando el tiempo de la discusión se prolonga. Proyectando la intersección de las curvas 
de beneficios y costos, los costos siempre terminan excediendo a los beneficios, por tanto la función de utilidad del argumentador disminuye a través del tiempo.

Cuando los argumentadores toman la decisión de participar en una discusión evalúan diversos factores, algunos de ellos son: las expectativas de cuán trabajoso será concluir exitosamente un compromiso argumentativo; el tiempo estimado para realizar lo anterior y la intuición de las funciones de costo y beneficio. Sin embargo, el tiempo no es solo importante para los costos de la argumentación, sino que también lo es para el valor percibido de los costos y beneficios, en tanto que, primero, los costos de argumentar ocupan un lugar más preponderante que los beneficios y peligros, ya que los costos son inmediatos y certeros, y por el contrario los beneficios y peligros son inciertos y diferidos. En consecuencia, los argumentadores ven a la argumentación como una estrategia óptima cuando el momento de llevarla a cabo está en el futuro, pero si ésta se realiza en un tiempo cercano los costos se convierten en una variable muy relevante.

Para P\&C, el peligro es entendido como la utilidad negativa producida por un efecto secundario o por una consecuencia de la discusión, que compromete algunas metas del participante. Aquí, específicamente, se analiza el peligro en cuanto implica un grado de responsabilidad personal, ya que éste puede traer consecuencias indeseables para el argumentador. Aun cuando los peligros asociados a una discusión dependen de las metas específicas del argumentador, hay riesgos que atraviesan la mayoría de las discusiones. El primero refiere a que un argumento puede fracasar, minando la credibilidad de la conclusión que se quiere probar. El segundo peligro alude a la posibilidad de que la discusión conduzca a un nuevo desacuerdo entre los participantes, en vez de resolver sus discrepancias. Hay cuatro factores que pueden contribuir al aumento del desacuerdo, estos son: 1) cualquier desacuerdo que sobreviva luego de la discusión será menos tolerado; 2) mientras más dura la discusión más posibilidades hay de perder y por lo tanto de no convencer a la otra persona; 3) el motivo del desacuerdo inicial puede ampliarse, apareciendo otros motivos de desacuerdo; y 4) el contexto social puede hacer aparecer a la actividad de argumentar como una práctica indeseada si se extrapola sin resolución a la vista.

El bienestar emocional también está asociado con los peligros de la argumentación. No es lo mismo participar de una discusión con un extraño que con un 
amigo o familiar, debido a que la discusión con éstos últimos implica a veces no hablar de ciertos temas para no dañarlos. Otro peligro es llamar la atención sobre asuntos que el argumentador no quiere hablar o mostrar. Además, la argumentación puede conllevar riesgos en la reputación del argumentador una vez se inician temas respecto de los que no tiene conocimiento u opinión formada. Como se observa, son varios los acentos que P\&C enfatizan con su visión funcional que considera costos, beneficios y peligros de la argumentación, factores mayores que, esclarecidos, evidentemente aportarían a una sistematización de una actividad que es más estratégica que dialéctica según estos autores.

\subsection{Funcionalidad y valor de la práctica argumentativa en la teoría estándar}

El estudio de la argumentación ha desarrollado su trabajo desde una perspectiva esencialmente funcional, aun cuando explícitamente esto no se reconozca del todo. En la teoría de los bloques semánticos (Ducrot, 2000, 2004; Ducrot y Carel, 2006), la argumentación es considerada como un proceso polifónico de enunciación en cuyo seno se juegan las marcas lingüísticas y semánticas de los topoi que una sociedad o grupo comparte. El ángulo funcional de la argumentación, en esta teoría, está relacionado con el hecho de que la actividad argumentativa diaria refleja, y funciona al servicio de, la coordinación entre los procesos sociales que zanjan y distribuyen los lugares de lo aceptable y lo prohibido en virtud del funcionamiento mismo de las lenguas naturales.

Algo similar ocurre, desde un punto de vista funcional, con el enfoque pragmadialéctico de la argumentación (van Eemeren y Grootendorst, 2002, 2004; van Eemeren, 2010), donde la argumentación es definida como una forma de resolver críticamente una diferencia de opinión, es decir, es una teoría en la que la funcionalidad de la argumentación es aún más específica respecto de la teoría de los bloques semánticos, pues se trata incluso de declarar, por ciertos procedimientos -o reglas para la discusión crítica- a una de las partes como depositaria de la razón respecto de la discusión en cuestión. Precisamente porque el enfoque pragma-dialéctico es una teoría del discurso que reúne, por una parte, una visión dialéctica de la argumentación, entendida como el trayecto que sigue una discusión crítica cuyo fin es resolver una diferencia de opinión, y por otra, una visión pragmática y retórica de los movimientos que se realizan en una 
discusión crítica, tanto los actos de habla como las reglas para la resolución cumplen la función de ir clarificando en el proceso tanto la definición de quién corre con el peso de la prueba, como las restricciones que cada parte debe respetar, hasta la fórmula para reconocer y declarar quién ha ganado la disputa.

Una inclinación aún más clara en el reconocimiento de las funciones de la actividad argumentativa, se encuentra en la lógica informal desarrollada por la Escuela de Windsor (Johnson, 2000; Johnson y Blair, 1977; Walton, 1989, 1992, 1997, 2004, 2007). La forma misma en la que se ha conceptualizado la lógica informal manifiesta esto. Por lógica informal se ha entendido un brazo de la lógica cuya función, tarea y objetivo es desarrollar estándares no-formales, criterios y procedimientos para el análisis, interpretación, evaluación, crítica y construcción de la argumentación en el discurso cotidiano. Uno de los elementos teóricos medulares de este acercamiento es que el modelo informal se alza como una alternativa a la noción de validez deductiva al poner el acento en tres criterios para evaluar la relación entre premisas y conclusión: 1) relevancia, 2) suficiencia, y 3) aceptabilidad. El primer criterio dice relación con el examen de la existencia o no de una relación sustantiva, pertinente, entre premisas y conclusión; el segundo, apunta a la verificación de si acaso las premisas proveen de suficiente evidencia para la consecución de la conclusión; y el tercero, se vincula con el examen de si las premisas son verdaderas, probables o engañosas. Incluso más contundente en su apreciación respecto de los beneficios funcionales de argumentar, Johnson (2000: 26-27) sostiene que: “los que participan en una argumentación incrementan su poder racional, desarrollan un sentido de respeto por la evidencia, desarrollan también un sentido de respeto por las diferencias de opinión, y un aprecio por la conducta crítica.” Pero, ¿cuál es la evidencia empírica que posee Johnson para estar seguro de tales beneficios? Si bien procede con un análisis filosófico para afirmar tales pretensiones, no entrega evidencia específica para respaldar su posición.

En el caso clásico de la obra de Toulmin (1958; Toulmin, Rieke y Janik, 1978), nos encontramos frente a un esfuerzo por desmontar la estructura de los argumentos y sólo en este sentido se podría ver una noción funcional, es decir, que entre las partes que Toulmin distinguió como estructura argumentativa se darían relaciones funcionales y no en una posición filosófica funcional de la argumentación, ya que Toulmin estuvo más 
interesado en intervenir en la discusión epistemológica de fines de los años de 1950 que en la construcción de una teoría de la argumentación.

En cada uno de estos acercamientos y teorías, no obstante, hay un prurito funcional, implícito o explícito. Frente a este escenario, y muy recientemente en el debate entre estudiosos del área, hay quienes, como Goodwin (2007), cuestionan sin vacilación que la argumentación, y el argumento en particular, tenga los beneficios y efectos que se asumen. Goodwin (2007: 70-71), discutiendo la posición pragmática y normativa de Walton, duda de si el contexto de un argumento deba ser concebido como una jointactivity (actividad conjunta); duda al mismo tiempo que tal actividad conjunta tenga la función de alcanzar un valor social, y que la exposición de argumentos siga un conducto normativo respecto del que los hablantes estén, consciente o inconscientemente, siguiendo. Patterson (2011), por su parte, duda del punto de vista de Goodwin señalando que el funcionalismo en la teoría de la argumentación, como en varios campos científicos, solo puede ser falseado una vez que se tenga la teoría en cuestión, esto es, el funcionalismo en cualquier teoría le brinda al investigador el objeto que los datos empíricos vendrán a desmentir. ${ }^{4}$

2.3. Críticas a la funcionalidad positiva (o bondadosa) de la argumentación desde la psicología del razonamiento

Desde la psicología cognitiva también ha habido observaciones al respecto. Recientemente, Sperber y Mercier (2012; Mercier, 2011a, 2011b, 2011c, 2011d, 2012; Mercier y Landemore, 2012; MercierySperber, 2009, 2011a, 2011b; Sperber, 2001; Sperber et al., 2011), han puesto en duda todos los avances provenientes de la teoría de la argumentación entre lingüistas y filósofos, al sostener que la argumentación y la

\footnotetext{
${ }^{4}$ Por problemas de espacio, se ha dejado fuera de la discusión el valor otorgado a la argumentación desde el punto de vista retórico. Para una reflexión de este punto, véase Bermejo-Luque (2007).Para un estudio acabado del valor que adquiere la argumentación retóricamente analizada, véase Tindale (2004), van Eemeren (2010).
} 
inteligencia corren por módulos paralelos y no siempre funcionan de forma coordinada, por lo que los resultados de un proceso argumentativo no están determinados por una evaluación estrictamente crítica de la mano de una depuración racional; sostienen además que los humanos argumentamos siempre con un sesgo de confirmación y que la evidencia en psicología cognitiva de los últimos 50 años muestra que, debido a este sesgo, los humanos argumentamos aquello que podemos justificar y no lo que sería una mejor opinión o argumento. Así concebida la actividad por Sperber y Mercier, de acuerdo con una vasta gama de experimentos y de datos citados por los autores, la argumentación no brinda ninguno de los beneficios y funciones positivas que a menudo se piensa tiene. Una de las conclusiones que más llama la atención de la posición de Sperber y su equipo, es que los humanos son en principio crédulos de aquellos en los que confían, pero tan luego como desconfían lo suficiente, recién allí resuelven cotejar más atentamente el contenido de los argumentos, poniendo en práctica un escaneo de la coherencia y relevancia de lo comunicado (lo que Sperber et al., 2010, llaman vigilancia epistémica).

Pero no fue Sperber ni Mercier y sus colaboradores quienes llamaron por primera vez la atención sobre la ilusión de que el razonamiento reporta resultados óptimos en la práctica argumentativa. La psicología del razonamiento tiene un amplio desarrollo que partió hace medio siglo en torno a, entre otros, los problemas del razonamiento hipotético, y que tiene hoy por hoy la teoría dual como una de sus protagonistas (Evans y Frankish, 2009; Evans, 2010; Johnson-Laird, 2008; Kahneman, 2011; Manktelow, Over y Elqayam, 2011; Oaksford y Chater, 2007;Santibáñez, 2012; Stanovich, 2011; Stanovich y Toplak, 2012). En una síntesis muy abreviada, se puede decir que desde el momento en que la mente está dividida, o compuesta por, dos sistemas, la actividad de razonar y exponer argumento se supedita a esta distribución cognitiva. De modo que habría un razonamiento intuitivo que produce un razonamiento rápido, heurístico, sin mediación de reflexión, y otro razonamiento propiamente reflexivo, lento, muy costoso en el gasto de energía cognitiva. Desde este punto de vista, la argumentación sería parte, o manifestación, del sistema 2, el que se caracteriza, desde el ángulo evolutivo, como un logro reciente, de trabajo consciente para el agente, que dispone de conocimiento explícito, controlado, lento, secuencial, abstracto, basado en ciertas reglas y vinculado en general a la inteligencia. El sistema1, por cierto, es lo 
opuesto. Así, la mente estaría, funcionalmente hablando, predispuesta con dos variantes de procesamiento de razonamiento. ${ }^{5}$

Para Dessalles (2007, 2011), que también ya se había adelantado a Sperber y Mercier, la argumentación nace como una capacidad cognitiva con una evidente tarea. Desalles sostiene que el modo argumentativo de conversación aparece cuando un agente trata de encontrar una solución a un conflicto cognitivo. Este último, a su vez, aparece cuando las creencias y deseos que constituyen el conflicto tienen cierto grado de intensidad contradictoria en el agente. Los humanos tenemos conflictos cognitivos cuando tenemos diferentes representaciones de una situación o respecto de los términos a través de los que marcamos la situación. De modo que, también en esta versión de las cosas, el razonamiento no tiene per se una cualidad bondadosa que lo constituya, pues solo se expresa partir de la colisión de representaciones.

\subsection{La funcionalidad argumentativa como problema comunicativo}

Para Hample, Warner y Norton (2006), no cabe duda que en el proceso argumentativo son muchos los factores que influyen en la forma en que la discusión se lleva a cabo y en cómo los participantes se desenvuelven en ella. Para los autores, una forma fructífera para iniciar este análisis funcional, a saber, distinguir los factores comunicativos y las funciones que cada uno de ellos juega en el acto comunicativo de la argumentación, es observar las predisposiciones, preconcepciones, expectativas y significados asociados a la actividad argumentativa.

Para tal efecto, y para apoyar el énfasis empírico, se ayudan con algunos conceptos clásicos en otras áreas de las ciencias sociales y la teoría de la comunicación.

\footnotetext{
${ }^{5}$ También por problemas de espacio, se dejará para otro trabajo toda la fructífera posición de la así llamada racionalidad ecológica (Gigerenzer, 2008; Todd, Gigerenzer, y Grupo ABC (2012), que postula que el razonamiento no es ni una ilusión, ni un óptimo cognitivo, ya que simplemente realiza con éxito las tareas para las que está entrenado y el ideal de lo óptimo es, no se debiera olvidar, muy problemático de definir.
} 
Una de las nociones fundamentales en esta visión es la de marco argumentativo. Este concepto es propuesto por Hample (2005), basándose en la idea de marcos de Goffman (1959, 1967, 1969). Goffman plantea que toda situación tiene un natural strip, esto es, una secuencia de acciones que a través de ciertas claves puede ser enmarcada o reenmarcada de otra manera, donde cada re-encuadre que se realiza conduce a una nueva laminación. De esta manera, en una situación de argumentación interpersonal, el intercambio de razones cara a cara sería el natural strip, el que puede ser enmarcado en contextoscomo el de juego, de dominancia, o de proyección de identidad. Es decir, es el sujeto hablante quien escoge, funcionalmente,el objetivo que persigue y qué marco selecciona en una situación comunicativa específica.

De acuerdo con esto, Hample (2005) describe tres categorías de marcos argumentativos utilizados por las personas. La primera contiene a los marcos primarios, en donde las personas se centran en sí mismas, en sus metas y deseos. Aquí hay cuatro sub-marcos: utilidad, dominancia, identidad y juego. La segunda categoría incluye el reconocimiento y la conexión con el otro argumentador, es decir, el argumentador toma en cuenta las metas y planes del otro. Este reconocimiento puede ser ejecutado de manera competitiva o cooperativa. La tercera categoría es denominada contraste profesional y se vincula con un entendimiento reflexivo de la argumentación, cercano a la perspectiva sostenida por los académicos que reflexionan sobre el problema de argumentar.

Otro aspecto teórico sensible en esta visión, es el de la edición de los argumentos. La idea es simple pero muy sugerente, y va en contra de los hallazgos en la psicología cognitiva. Los individuos editan (revisan, sopesan, filtran) los argumentos que procesan en virtud del escenario, el tema, la audiencia, los objetivos, el tiempo, la energía, etc., y esa edición puede estar influenciada por muchos factores, tales como las reacciones emocionales hacia la actividad argumentativa y los propios marcos argumentativos. Según Hample (2005), la edición estaría entre la producción privada inicial de un mensaje y la producción pública final de éste. De este modo, los sujetos difieren en el grado y en los estándares con los cuales editan sus argumentos. Por ejemplo, hay quienes no editan en absoluto y que en consecuencia pertenecen a los marcos primarios, los llamados individuos blurters. Quienes editan, a su vez, sus 
argumentos tomarían en cuenta el daño que podrían provocar al otro con lo que enuncian.

Los estándares editoriales se pueden dividir en tres clases. Elprimero tiene relación con la efectividad, en la que el foco está en si los argumentos pueden ser rechazados debido a que no funcionarían o porque son muy negativos para utilizarlos. La segunda clase se denomina centrada en la persona; aquí la principal preocupación es el posible daño que se puede causar a sí mismo o a la otra persona con la enunciación de un argumento en particular. Por último, la tercera clase se denomina competencia del discurso, en el que las personas ponen atención a los argumentos que pueden ser rechazados por ser irrelevantes o erróneos.

Interesante de notar es que tanto los marcos argumentativos como el comportamiento editorial marcan diferencias en la forma en cómo las personas se presentan y desenvuelven en la actividad argumentativa. Estas diferencias individuales se acompañan de otras como la agresividad verbal y la agresividad argumentativa. La primera apunta al ataque hacia la identidad y sentimientos de la otra persona, y la segunda refiere a los esfuerzos por comprometer la posición que sostiene el oponente. Ambas se relacionan con ciertas creencias y comportamiento básicos como son la dominancia y la hostilidad, que podrían respaldar la tesis de los autores de que hay una conexión entre los marcos argumentativos y los estilos de edición. El género y la reactancia psicológica también son diferencias individuales que pueden estar implicadas en el uso de ciertos marcos y estándares editoriales a la hora de elaborar argumentos. Respecto del primero, se ha encontrado que hombres y mujeres difieren en la agresividad verbal y argumentativa; y en cuanto a la reactancia psicológica, Hample la describe como el impulso de la persona de resistir bajo presión. En este sentido, según los autores, ésta podría ayudar a comprender por qué las personas retroceden o conceden cuando se encuentran bajo presión en una discusión. También suponen que las diferencias entre las personas en cuanto a la reactancia psicológica pueden tener relación con diferencias en los marcos argumentativos y los estilos editoriales.

También se han encontrado (Hample, 2005) relaciones entre los marcos argumentativos y el género. Por ejemplo, se ha hallado que lo masculino se vincula con la perspectiva de que la meta principal en una discusión es la de ganar, por lo que está asociada a los marcos primarios. En cambio, la femineidad se relacionaría con la 
cooperación y por consiguiente con el segundo y tercer marco argumentativo. Dentro de la argumentatividad hay dos sub-escalas: aproximación a la argumentación y la evitación de la argumentación. Las personas que tienen un alto puntaje en la primera editan menos, en cambio los que tienen alto puntaje en la segunda prestan mucha más atención al daño que le pueden provocar al otro al usar un argumento. Sobre la base de esto, los autores suponen que los marcos primarios se relacionan con la orientación hacia la efectividad en la elaboración de un argumento; que el tercer marco y la cooperación se vinculan con la edición centrada en la persona; que la agresividad verbal se asocia con orientaciones hacia la dominación y competitividad; y por último, que las personas que puntúan alto en argumentatividad, editan menos y no se preocupan por no dañar a los otros con sus argumentos.

Estas generalizaciones teóricas fueron producto de una investigación en la que se encuestaron a 205 estudiantes universitarios de Estados Unidos, donde aproximadamente la mitad eran hombres y la otra mujeres. La edad promedio fue de 19.9 años. A partir de lo respondido por los participantes, las principales relaciones encontradas fueron: hablar sin editar (blurting) se asocia negativamente con ver los argumentos como opciones constructivas, pero se correlaciona positivamente con ver los argumentos como algo útil que ayuda a conseguir las metas personales. La investigación también mostró que un alto puntaje en masculinidad se asocia con el uso de marcos como el de utilidad y juego y al hablar sin editar, y un alto puntaje en femineidad se relaciona con el tercer marco argumentativo de contraste profesional y la cooperación. Además, señalan que las personas con una alta motivación para entrar en una discusión, con un alto puntaje en ítems de agresividad verbal y altamente reactivas, ven a la argumentación de forma utilitaria que está al servicio de la identidad, que cumple funciones de juego y que puede servir para dominar a la otra persona.

Sin duda, un aproximación teórica a tono con datos reales provenientes de estudios empíricos sobre ecologías argumentativas daría un cuadro más adecuado de cómo hablantes naturales consideran que sus acciones argumentativas están sujetas a ciertos parámetros normativos, pues de la valoración y función otorgada se desprendería un tipo de regulación ética o, al menos, de procedimiento instrumental con arreglo a fines. 


\section{Estudios Empíricos}

A partir de las coordenadas socio-culturales de las distintas comunidades de habla, es razonable esperar que el valor y función que un colectivo le otorga a argumentar varíen. Así lo han demostrado una serie de investigaciones contemporáneas (Hample, 2005; Hample, Warner y Young, 2009; Hample, Han y Payne, 2010; Ricco y Sierra, 2011), llevadas a cabo en distintas realidades sociales. De acuerdo con estas investigaciones y resultados, los hablantes argumentan, por ejemplo, porque buscan alcanzar beneficios individuales, conducta que está en directa relación con una cultura competitiva e individualista, como es el caso entre estudiantes universitarios norteamericanos (Hample, 2005; Hample, Han y Payne, 2010). De este modo, entre estos sujetos se apreciaría una visión utilitarista de la actividad de argumentar, que se puede contraponer a otro valor y función otorgada a la actividad de argumentar, puesto que estos investigadores también han reportado que ciertos individuos (profesionales de clase media norteamericana) valoran la argumentación como una actividad que facilita el entendimiento y la negociación.

En el caso de los estudios empíricos de la Escuela de Ámsterdam, se han limitado a testear la validez convencional de las reglas de discusión de la pragmadialéctica. De acuerdo con los autores (van Eemeren, Garssen yMeuffels, 2009), el trabajo consistió en medir la aceptabilidad intersubjetiva de las reglas para una discusión crítica entre hablantes ordinarios -holandeses, alemanes, ingleses, españoles, indonesios- que no tuvieran ningún entrenamiento formal en teoría de la argumentación o en el reconocimiento de falacias, confrontados estos hablantes a fragmentos de discusiones en los que habían movimiento no falaces (válidos, aceptables) y falaces. El estudió cubrió un amplio espectro de falacias informales (de los ataques ad hominem en sus tres variantes -abusiva, circumstancial, tu quoque- hasta falacias como la falsa analogía). Este estudio no es nuevo en la teoría de la argumentación. Los autores señalan (2009: 33) que el trabajo empírico pionero de Bowker y Trapp (1992), que 
buscaba descifrar si hablantes naturales aplicaban criterios consistentes y predecibles a partir de los que distinguían entre argumentación válida e inválida, tuvo varias deficiencias metodológicas. ${ }^{6}$ En su estudio (van Eemeren, Garssen yMeuffels, 2009),los autores comienza ejemplificando el trabajo metodológico con el análisis de las falacias ad hominem. 92 respondientes, estudiantes holandeses de entre 16 y 17 años de edad, evaluando con lápiz y papel 48 fragmentos de situaciones controversiales ordinarias. Una crítica inicial a esta investigación es si jóvenes de 16 a 17 años en efecto pueden evaluar diálogos argumentativos respecto de si son razonables o no razonables, dicho de otra forma, si acaso han desarrollado las competencias cognitivas -cierta madurez que requiere el ejercicio. Lo llamativo de esta investigación es que confirman y validan todas sus reglas a través de esta intersubjetividad (lectura de diálogos inventados), en relación con falacias ad hominem, concluyendo que jueces normales (jóvenes de 16 y 17 años) hacen una distinción tajante entre movimientos razonables y no razonables, que distinguen entre las tres variantes de este tipo de falacias (y que como ya sostenía la teoría, la variante abusiva es la más falaz), que tal identificación de falaz de estos movimientos que tienen un carácter personal no se debe a una explicación del tipo cortesía social, y que tales jueces normales no pueden manifestar a nivel abstracto la razón normativa por la que encuentran falaz lo que encontraron falaz. Luego de dar cuenta de este trabajo piloto, los autores van pasando una a una las etapas de una discusión crítica (confrontación, apertura, argumentación y conclusión) con las respectivas falacias identificadas como relacionadas a cada etapa, y nuevamente confirman lo que la teoría ya había predicho.

En el contexto iberoamericano, el estudio empírico de la actividad argumentativa ha estado más asociado al problema de la complejidad argumentativa que al problema de la razonabilidad y, por tanto, de la normatividad. Sin embargo, si se analizaran los datos obtenidos desde este último punto de vista, se podría avanzar bastante en tal

\footnotetext{
${ }^{6}$ También sintetizan el trabajo de Schreier, Groeben y Christmann (1995), que aquí no se puede comentar por falta de espacio.
} 
dirección ya que, por ejemplo, Jélvez (2008) procuró establecer los esquemas argumentativos más frecuentes en los textos escritos producidos por un grupo de estudiantes pertenecientes a tercer año de enseñanza media en Chile, y ya se había apuntado que al investigar el uso de esquemas argumentativos se puede proyectar el tipo de razonabilidad de fondo de los hablantes. En una línea también convergente, Meza (2009) trabajó en torno a los aspectos dialécticos y retóricos que emergen de las interacciones argumentativas de estudiantes de tercer año de enseñanza media de dos establecimientos educacionales de la Región de Valparaíso de Chile, siguiendo en esto a la teoría pragma-dialéctica de van Eemeren. De naturaleza análoga es, por ejemplo, el objetivo que trabajó Marinkovich (2000), al procurar establecer el perfil de la competencia de escolares chilenos en la producción del discurso escrito en dos tipologías textuales. Utilizando explícitamente la noción de complejidad argumentativa, Padilla y López (2011) describen el alcance de la misma en estudiantes universitarios de humanidades en la ciudad de Tucumán, Argentina, estableciendo, entre otras conclusiones, que el $40 \%$ de los textos escritos por los estudiantes ni siquiera alcanza el grado mínimo de “Argumentatividad” (que ellas midieron en función de si el hablante esgrimió argumentos que respaldaran el punto de vista emitido).

Si la información contenida en estos trabajos pudiese analizarse en la perspectiva de responder cuál podría ser la(s) función(es) principal(es) y el valor(es) otorgado(s) a la actividad argumentativa, con mayor facilidad podría resolverse el puzzle de la normatividad, puesto que desde el reconocimiento de funciones por parte del hablante se deberían rastrear los tipos de reglas que estarían a la base de las mismas.

\subsection{Ecología argumentativa en Chile. Valor y función en jóvenes universitarios}

Para el efecto de ir respondiendo la inquietud apuntada en el párrafo anterior, hemos comenzado en Santiago de Chile una investigación empírica cuyo objetivo principal es precisamente conocer qué funciones y valor le otorgan a la actividad argumentativa jóvenes universitarios de universidades privadas y públicas. Los datos que en la siguiente sección (4) se discuten, han sido obtenidos de la investigación desarrollada durante el año 2013: la primera es "Valor, función y complejidad argumentativa en estudiantes universitarios: el caso en las regiones de Coquimbo y Metropolitana”, 
subsidiada por el Fondo Nacional de Ciencia y Tecnología de Chile, proyecto No. 1130584 (en adelante VFC).A continuación detallamos la metodología y los principales resultados preliminares.

\subsubsection{Marco metodológico ${ }^{7}$}

Entre las preguntas de investigación que guiaron el trabajo, se encuentran: $1 . ¿$ Cuán importante es para los jóvenes chilenos de educación superior poner en práctica la capacidad de argumentar?; 2. ¿Qué variables socio-culturales y cognitivas determinan la valoración y funcionalidad atribuida por los estudiantes de educación superior a la práctica de argumentar?;y 3.¿Cómo valoran y qué función le otorgan a las prácticas de mantener un disenso, consensuar y abstenerse de opinión en situaciones de controversia o cuestionamiento? El objetivo general para esta etapa de la investigación fue: 1)Analizar y comparar las claves socio-culturales y cognitivas que determinan la valoración de la facultad cognitiva y lingüística de argumentar, a partir de variables de identificación como: Universidad pública/privada; sexo; grupo socio-económico; tipo y año de carrera (en las tablas de contingencia en los resultados se puede observar las categorías de esta última variable); los objetivos específicos para esta etapa fueron: 1.Clasificar y analizar las variables socio-culturales y cognitivas en estudiantes universitarios de distintas carreras que determinan la valoración y funcionalidad de la práctica de argumentar; 2.Analizar los tipos de marcos argumentativos (Hample, 2005) utilizados en la práctica argumentativa de los distintos tipos de jóvenes universitarios de acuerdo con variables socio-culturales.

El estudio tuvo carácter cuantitativo, un alcance descriptivo y los sujetos en estudio fueron jóvenes universitarios que cursan pre y postgrado en universidades públicas y privadas, de distintas disciplinas de la ciudad de Santiago. Se seleccionaron

\footnotetext{
${ }^{7}$ Agradezco el apoyo de Sahara Martignoni quien efectúo el análisis estadístico.
} 
estudiantes de las disciplinas representativas de las facultades de Ciencias Sociales y Humanidades que tienen las universidades seleccionadas, a fin de poder comparar de forma consistente, en esta etapa preliminar de investigación, sujetos con perfiles similares. Se procuró un balance adecuado entre los distintos años de cohorte para comparar adecuadamente a quienes se encuentran en el inicio, en fase intermedia o en la fase terminal de sus estudios de pre o postgrado. El instrumento aplicado fue una encuesta cuya muestra estuvo compuesta por jóvenes universitarios de las siguientes universidades: Diego Portales y Alberto Hurtado (privadas), de Santiago y de Chile (públicas). El universo estuvo definido por los estudiantes registrados en las casas de estudios en programas de pre y post grado de todas las disciplinas que se imparten en tales universidades de las facultades escogidas. La muestra final obtenida en el trabajo de campo fue de 384 casos, considerando 96 casos por cada una de las universidades elegidas previamente (muestreo por conveniencia). Para la determinación de los 384 casos, se consideró que el universo es finito (matricula de alumnos de cada universidad), con un nivel de confianza del 95\% y de error un 5\%.

El instrumento fue un cuestionario en el que se combinaron preguntas cerradas codificadas con escalamiento Likert y Diferencial semántico. Las variables fueron:

1) Identificación básica: Edad, género, ingreso familiar, años en universidad, disciplina;

2) Argumentatividad: disposición a participar en la actividad de argumentar;

3) Agresividad verbal: uso de estrategias de ataque para enfrentar situaciones de controversia; 4) Marcos argumentativos: identificación de meta-objetivos que los sujetos reconocen como razones para argumentar (Hample, 2005);

5) Individualismo/colectivismo: identificación de valores culturales asociados a la práctica argumentativa;

6) Poder: identificación de función del argumento y la argumentación en situaciones jerárquicas;

7) Auto-constricciones: reconocimiento de limitaciones y/o motivaciones sociales y cognitivas para argumentar;

8) Cortesía: medición de tendencias de cuidado a terceros en situaciones de discusión.

Para ejemplificar la estructuración de la encuesta en su forma de escala Likert (a partir de Hample, 2005), véase la siguiente reproducción de parte del instrumento: Instrucción general: Para los siguientes ítems responda utilizando la siguiente escala: 1= Estoy muy en desacuerdo, 2= Estoy en desacuerdo, 3= No contesta (neutral), 4= Estoy de acuerdo, 5= Estoy muy de acuerdo.

Marco de Identidad (solo algunos ítems):

1. Utilizo argumentos para mostrar mi capacidad intelectual.

2. Otras personas utilizan argumentos para mostrar sus capacidades intelectuales.

3. Los argumentos son útiles para demostrar lo que creo.

4. Los argumentos son útiles para demostrar lo inteligente que soy. 
5. Puedes aprender mucho sobre otra persona mirando el tipo de cosas que él o ella dice durante una discusión.

6. Una discusión puede revelar mucho sobre el carácter de una persona, tanto como una conversación amistosa.

7. Utilizo los argumentos para ganar respeto.

8. Puedes ver lo mejor o lo peor de una persona cuando ellos discuten con otros.

Marco de Juego:

9. Discutir es entretenido.

10. Discutir es, a veces, solo una manera de pasar el tiempo entre dos amigos.

11. Me gusta desafiar lo que otra persona dice solo para ver que más dirá.

12. A veces digo cosas que pueden resultar indignantes para entretenerme defendiéndola.

\section{Marco de Dominancia:}

13. Argumentar exitosamente es una manera de dominar a la otra persona.

14. Perder una discusión significa que la otra persona me domina, al menos en ese momento.

15. Cuando estoy en una discusión, ganar es más importante que ser amable.

16. Cuando estoy en una discusión, ganar es más importante que estar en lo correcto.

17. No me importa lo que trata la discusión, sino que quién tiene el poder sobre quién.

18. Cuando estoy en una discusión, siento que siempre tengo que ganar.

El análisis de los datos se desarrolló a través del uso del programa estadístico SPSS, y lo que a continuación se reporta son los resultados de cruzamientos entre las variables indicadas.

\section{Principales resultados y discusión}

El siguiente gráfico proporciona una estadística general respecto de valor, función y uso de un movimiento falaz: 


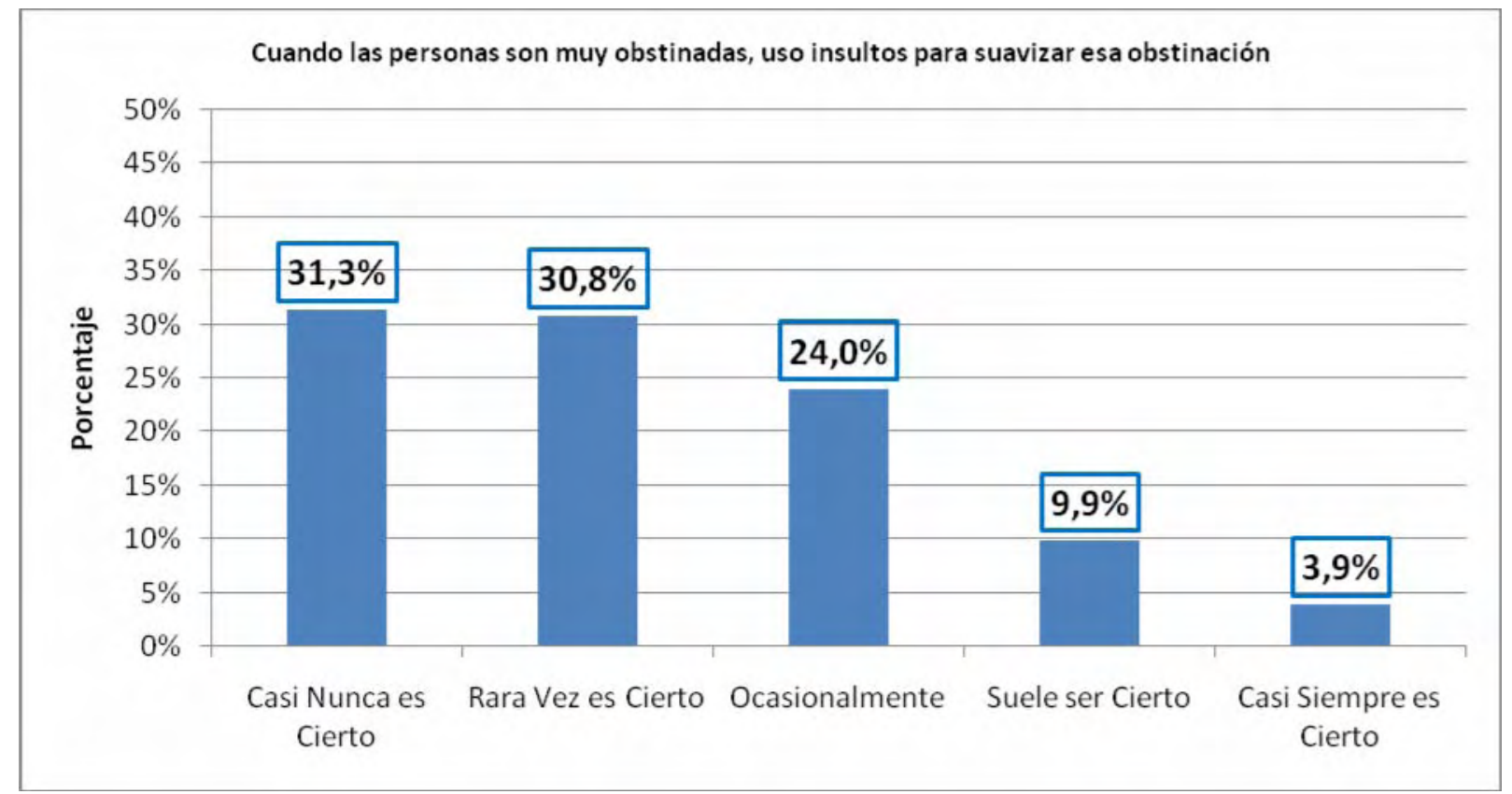

Gráfico 1. Fuente: Investigación 2013VFC.

Como se observa, existe un rechazo general al uso de un movimiento que, como toda la literatura lo señala, se valoriza como falaz. Pareciera que hay una coincidencia con los resultados de la escuela Pragma-dialéctica (van Eemeren, Grassen yMeuffels, 2009). Sin embargo, a medida que los jóvenes encuestados avanzaban en el cuestionario, y los ítems eran de mayor complejidad, se evidenció lo que podría verse como una valorización contradictoria de lo que consideran falaz. Véase la siguiente información:

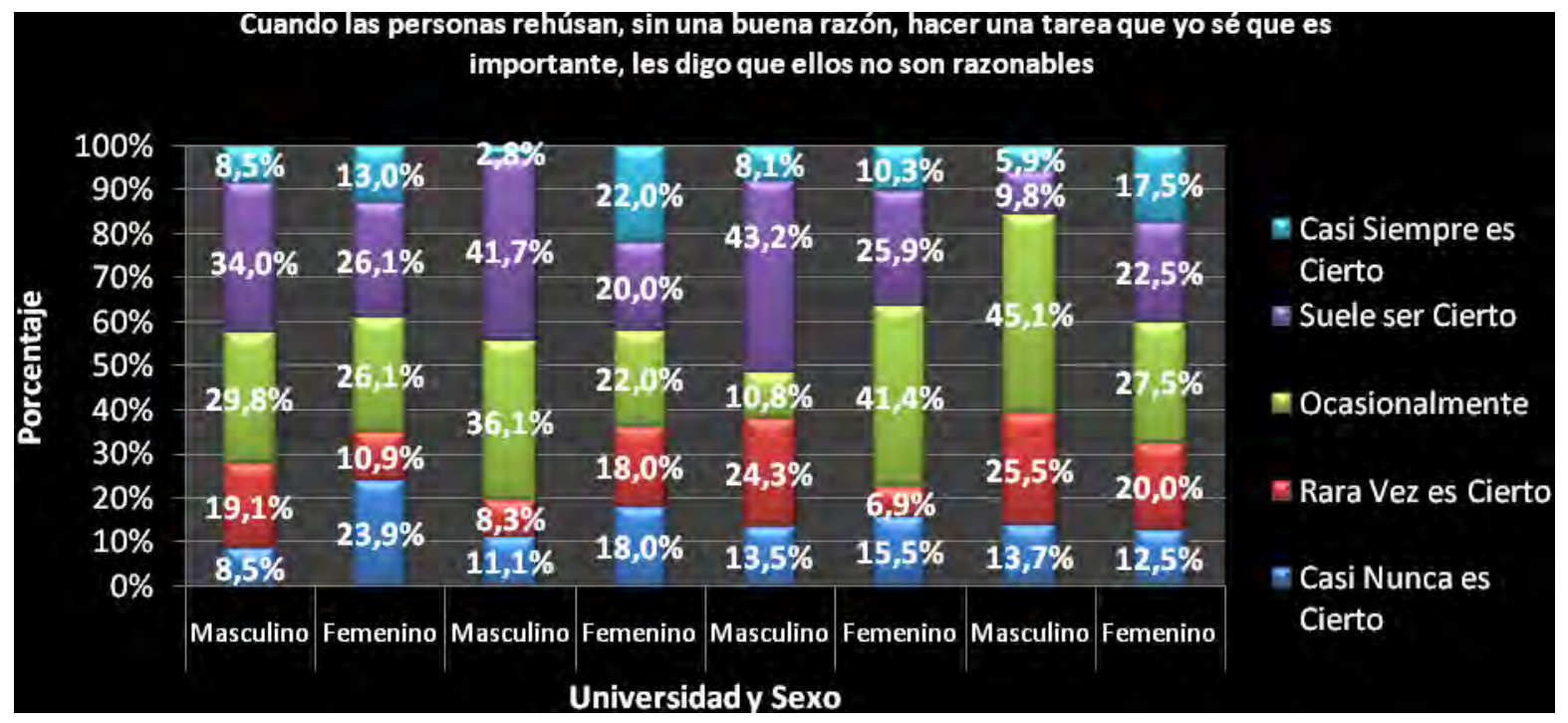

Gráfico 2. Fuente: Investigación2013 VFC. 
En este gráfico la información es mucho más detallada que en el anterior, donde solo se mostraban los totales. Aquí la afirmación ha sido analizada en virtud de las variables de identificación Universidad y Sexo. Llama la atención que, considerando una visión general, el mayor porcentaje de identificación positiva se encuentre en la proactitud de calificar a alguien como no-razonable si no realiza una acción que se concibe importante, sin que medie, además, una buena razón de rechazo a esa acción. Calificar a alguien como no-razonable puede ser visto, contexto mediante, como un ataque personal y de esa forma como una falacia. Es importante cualificar este análisis con la idea de contexto mediante, ya que la categoría ocasionalmente en este ítem puede verse como un síntoma de que el encuestado evalúa los factores del contexto para expresarle a alguien si es o no no-razonable. También llama la atención de esta información que en promedio la identificación con la valoración no-razonable esté inclinada hacia los estudiantes hombres y que, entre ellos, los de universidades públicas se identifiquen aún más con esa valoración. Esta evidencia, a su vez, podría ser vista como síntoma de coincidencia con los resultados de Hample (2005), respecto de que el hombre establece relaciones más directas en términos argumentativos, en virtud del marco dominancia que suele orientar su acción argumentativa.

En el siguiente gráfico, hemos querido contrastar el análisis anterior considerando la variable ingreso familiar: ${ }^{8}$

\footnotetext{
${ }^{8}$ Para efectos referenciales, los tramos de ingreso familiar aquí utilizados en pesos chilenos corresponden a los siguientes valores en euros (aproximado): tramo 1 menos de 800 euros;tramo 2, entre 801 y 4000 euros; tramo 3, más de 4001 euros.
} 


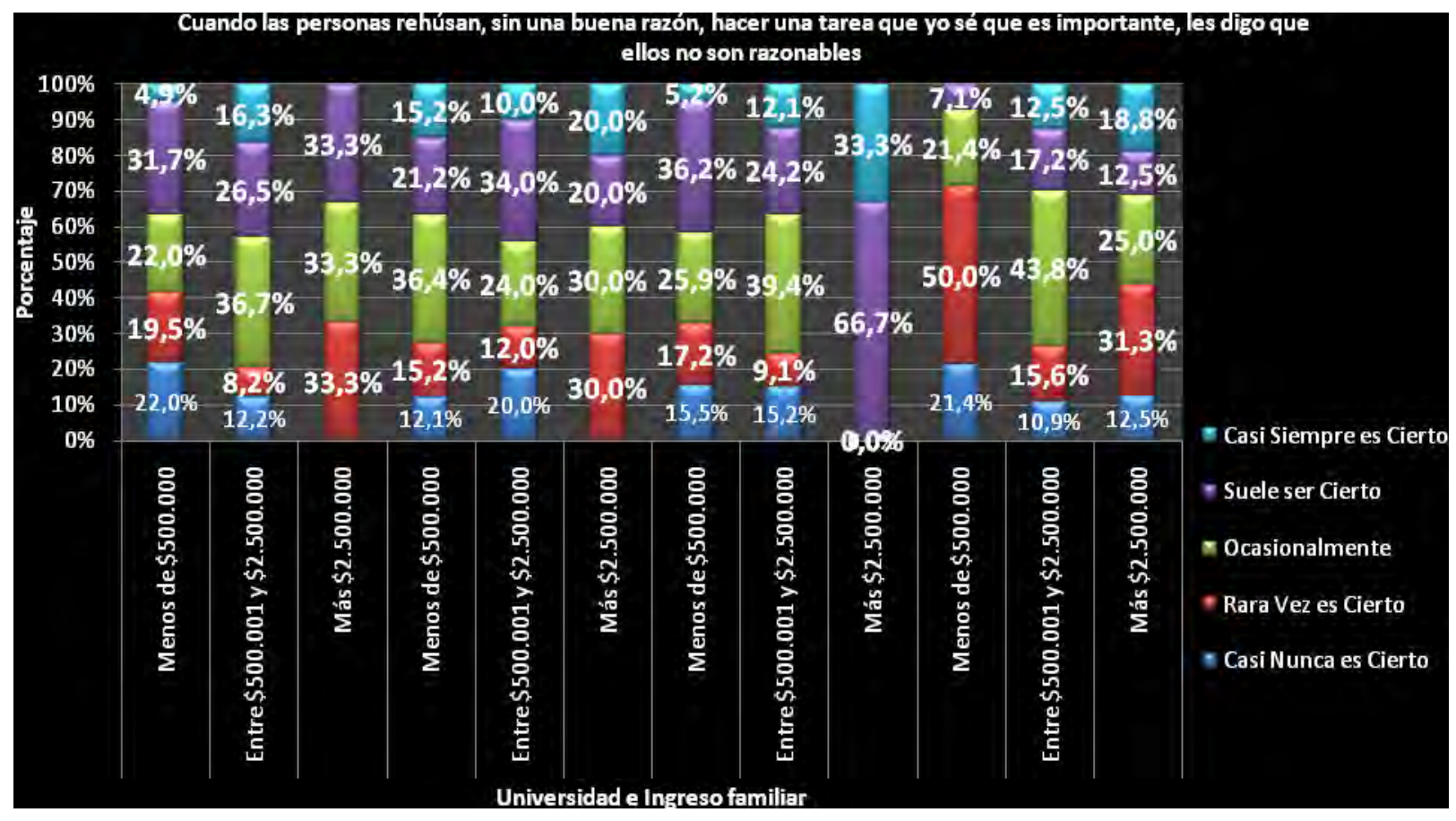

Gráfico 3. Fuente: Investigación 2013 VFC.

Aquí se observa que, en general, a mayor riqueza mayor apertura hacia expresar la norazonabilidad de un par en el contexto de la situación postulada, siendo el caso que entre los más ricos, en 3 de las 4 Universidades investigadas, no existe identificación con que lo planteado no sea nunca el caso. Esto es interesante, ya que la cortesía y la atenuación son aliados estratégicos en situaciones controversiales y su no consideración (como queda demostrado en estos gráficos entre hablantes jóvenes) podría estar mostrando un cambio cultural en la valoración y función atribuida a la argumentación.

Sin embargo, el siguiente gráfico vuelve a plantear una duda en el análisis. 


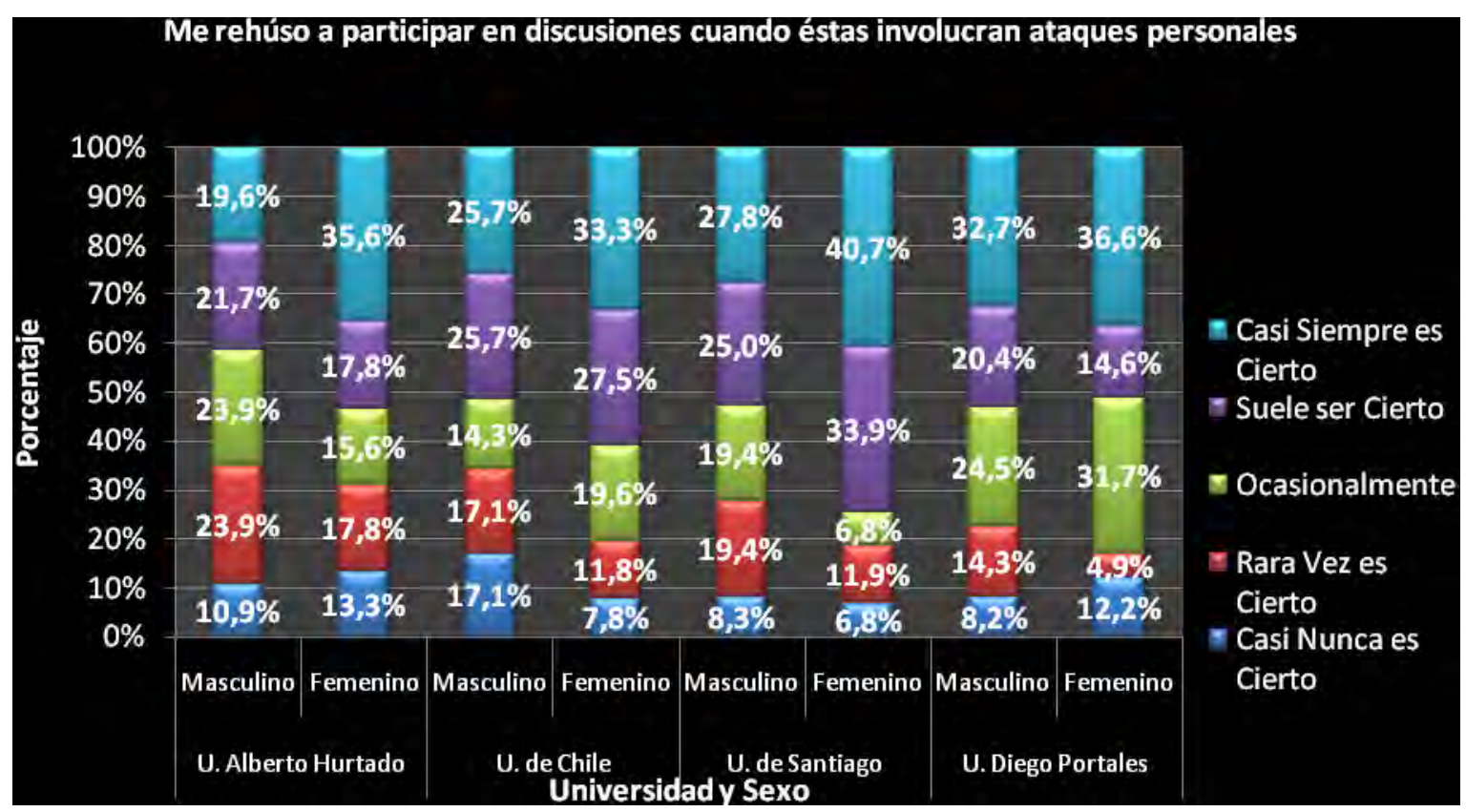

Gráfico 4. Fuente: Investigación 2013VFC.

Aquí somos testigos de que sin distingo entre sexo y tipo de universidad, la vasta mayoría considera que las discusiones que contienen ataques personales son indeseadas. Este dato, en cierta medida, está en contradicción con la pro-actitud de enrostrarle a alguien su falta de razonabilidad, ya que es poco probable que el oyente no considere tal expresión como un cierto tipo de ataque personal. Una lectura distinta de los datos, no obstante, podría enfatizar que en el caso anterior la afirmación involucraba directamente la auto-evaluación actitudinal verbal (es decir, “yo diría y haría tal y tal en este contexto”), mientras que esta última situación sólo se le pide al encuestado que acepte/rechace involucrarse en una discusión que contiene ataques personales sin especificar que él o ella exprese tales ataques.

Siguiendo la propuesta de Hample (2005) respecto de la funcionalidad que le otorgan a la argumentación para sí mismos y para terceros los hablantes en el contexto de un marco instrumental, en el caso de los jóvenes universitarios en Chile se da lo siguiente (en adelante ver información de los gráficos en el anexo). Existe (ver gráficos 5 y 6 en anexo) una similitud y consistencia notable respecto del "acuerdo" o "muy de acuerdo” con que los hablantes vinculan la argumentación a la dimensión instrumental, que en este caso se relaciona con que la argumentación permite mostrar la capacidad intelectual (tanto en auto-referencia como en referencia a terceros). Pero llama la atención el 17\% de “muy en desacuerdo” de mujeres de la universidad privada Alberto 
Hurtado en Santiago. No hay mayor margen para la especulación, ésta es una universidad privada, cuyos precursores son jesuitas y que recibe mayormente estudiantes del cuarto al sexto decil de los tramos socio-económicos en Chile. Quizás, entonces, exista una timidez de base en las mujeres jóvenes chilenas de estratos económicos medios y bajos relacionada con la postergación ya histórica de estos estratos en el acceso a los bienes culturales y sociales que redunda en una inseguridad a la hora de actuar en escenarios públicos. Siguiendo a P\&C (2011), discutidos anteriormente, desde el punto de vista funcional habría que agregar a los costos, beneficios y peligros de argumentar, la idea de obstaculizadores sociales. Cuando se les consultó sobre una propiedad evidente de los argumentos, a saber, "los argumentos son útiles para demostrar lo que creo” (ver gráfico 7), sorprendentemente un 21\% del total de los hombres (de las 4 universidades) cuyos ingresos familiares corresponden a los tres deciles más ricos del país, se manifestó “en desacuerdo” o “muy en desacuerdo”, y también un 5,3\% de mujeres del mismo tramo económico se manifestó “en desacuerdo” (no se observó “muy en desacuerdo” en ellas). Nuevamente, sólo cabe hacer vínculos generales. Que se asuma en los estratos altos que los argumentos no son útiles para expresar lo que uno cree, probablemente se vincule con el conservadurismo de la sociedad chilena que se manifiesta, o pone en práctica, a través de una socialización que enseña a los jóvenes inhibir sus puntos de vista y auto-editarse constantemente, y que no da espacios al comportamiento novedoso o autónomo. Dicho de otra forma, pareciera que los jóvenes de estratos socio-económicos altos en Chile estuvieran diciendo que no es con los argumentos con los que se expresan creencias, sino con otras marcas de carácter social (status, poder, clase social, etiqueta, membresías).

En relación con el marco juego, es decir, si los estudiantes otorgan un valor y función lúdica a la argumentación, se pudo observar que frente a la afirmación "Me gusta desafiar lo que otra persona dice, solo para ver qué más dirá” (ver gráfico 8), solo los estudiantes (hombres y mujeres) de la Universidad de Chile (la principal universidad pública y laica del país) se expresan claramente a favor de esa visión y uso. Esto podría estar relacionado con el tipo de cultura deliberativa más cotidiana en esa casa de estudios que flexibiliza o relaja el uso y/o objeto de argumentar. Respecto del marco de dominancia, los resultados arrojan distintivamente (ver gráfico 9) que los hombres delos 
tres deciles más ricos del país están “de acuerdo” o “muy de acuerdo” que “Argumentar exitosamente es una manera de dominar a la otra persona”, lo que vendría a confirmar una tendencia de uso por grupo social de la argumentación, y de género, pues también en el tramo de menos ingresos los hombres superan a las mujeres en porcentaje, y solo en el tramo de ingresos medios las mujeres superan levemente en porcentaje.

Los gráficos 10, 11 y 12 (ver anexo) entregan una información valiosa. Todos valoran altamente ser flexibles en una discusión, pero en su totalidad, cruzadas las respuestas por tipo de universidad y sexo, las mujeres se muestran más proclives a esa conducta cooperativa. El mismo ítem medido por sexo y año en la universidad, muestra que las mujeres con más años en la universidad, es decir más maduras o experimentadas, se identifican aún más con este valor de la flexibilidad que se vincula con la cooperación y la búsqueda de consensos y/o negociación. Requerida esta misma información de forma directa, a saber, "las discusiones implican cooperación de las partes involucradas”, categóricamente las mujeres se identifican más que los hombres con este marco argumentativo y conducta comunicativa pro-social (ver gráficos $13 \mathrm{y}$ 14). Nuevamente, hay una coincidencia con los resultados de Hample (2005).

¿Existe una concepción normativa de la argumentación que aflore de forma natural entre los jóvenes universitarios chilenos? En la investigación aquí reportada, se puede responder esta pregunta utilizando la información que arrojan los gráficos $15 \mathrm{y}$ 16. Éstos reflejan las respuestas a si "Las discusiones implican una solución exitosa de los problemas" y si "Discutir con una persona crea más problemas que los que resuelve”, respectivamente. De acuerdo con la primera consulta, hay una expresión de duda generalizada que este sea el caso (sumando los porcentajes de "ni de acuerdo ni en desacuerdo”, “en desacuerdo” y “muy en desacuerdo”), es decir, para los jóvenes las controversias no tienen la bondadosa finalidad de resolver un diferendo, con lo que se implica que la exposición de razones y razonabilidad no asegura disolver las diferencias de opinión que originan a tales problemas. Sin embargo, en general tampoco consideran que tenga el efecto contrario, a saber, que produzca más problemas, de modo que argumentar para los jóvenes no generaría beneficios ni costos directos, y que la actividad de argumentar sería una arena sustancialmente retórica, en el sentido de que todo depende del contexto, el tema y las personas involucradas. 
Al consultar sobre los costos cognitivos y emocionales de argumentar (gráfico 17: “Cuando termino de argumentar con alguien me siento nervioso y molesto”), los jóvenes inesperada y mayoritariamente señalan que no causa ninguna de los dos estados, ni molestia ni nerviosismos. Se señala aquí que esto es inesperado porque se puede interpretar este dato como en tensión con el hecho de que los jóvenes no estiman que discutir permita la resolución exitosa de problemas. La tensión está en que si no hay costos cognitivos, los individuos debieran apreciar que la argumentación sostenida en el tiempo genera el beneficio de aclarar y resolver controversias. Probablemente en esta respuesta se refleje un sesgo de racionalización por parte de los estudiantes, atribuyéndose ellos mismos las características de espíritu tranquilo y maduro, rasgos apreciados en la cultura de los adultos. En relación con una tendencia colectivista o individualista, la información de los gráficos 18 y 19, que reflejan la consulta por un mismo ítem ("Me desagrada participar en discusiones grupales”, analizado por sexo/carrera, y sexo/año ingreso a la universidad, respectivamente), se observa que los jóvenes en Chile se orientan colectivamente (no les desagrada), que a mayor madurez menor es el desagrado, y que los estudiantes de derecho (hombres y mujeres) son los más proclives a participar en discusiones colectivas, probablemente esto último debido a un entrenamiento de la profesión que estudian.

\section{Conclusiones}

A diferencia de los resultados de van Eemeren, Garssen y Meuffels (2009), la información entregada por los jóvenes universitarios chilenos muestra que ellos no le adhieren a la actividad argumentativa un valor de corrección de creencias y resolución de conflictos, ya que hay, en general, una menor apertura a discutir, siendo el caso entre los jóvenes de la clase alta uno muy llamativo: a mayor dinero, menor exposición de creencias.

Por otra parte, sí hay coincidencias con Hample (2005) respecto de los marcos argumentativos que impulsan la práctica argumentativa en los jóvenes. Destaca el hecho de que las mujeres exhiben una tendencia mayor a la flexibilidad y la colaboración argumentativa; que los hombres se muestran deudores de un marco de dominancia, y que los estudiantes de la Universidad de Chile (institución seno de la cultura laica y de 
los principales líderes políticos en Chile) conciben la argumentación también como una actividad lúdica.

Para finalizar estas reflexiones, es importante enfatizar que hay menos noticias para un optimismo teórico. Leitão (2000, 2008), por ejemplo, ha considerado que la actividad argumentativa tiene por esencia una función epistémica, incluso de mejoramiento epistémico. Lamentablemente, nos encontramos con culturas argumentativas en las que la exposición de creencias está inhibida, aunque esto sea una estrategia por parte de tales hablantes.

Del mismo modo, no se observa con claridad que la argumentación represente, o sea parte de, un mecanismo meta-cognitivo que monitoree de forma lineal la producción de razones, como parece que Fletcher y Carruthers (2012) sugieren. Más bien se trataría de una competencia individual (capacidad de producir razones y argumentos complejos) en función de una sensibilidad cooperativa (adecuación al contexto). Si estas ideas van por el camino correcto, o lisa y llanamente son equívocos profundos, más investigación empírica se requiere. He aquí el desafío.

Bibliografía

De Angelis, G. (2012). The Conventional Validity of Pragma-dialectics: A Critical Assessment and a suggestion for Theoretical Improvement. Cogency 4 (1): 9-24.

Bermejo-Luque, L. (2007). La concepción retórica del valor de la argumentación. En Santibáñez, C. y B. Riffo (eds.), Estudios en Argumentación y Retórica. Teorías Contemporáneas y Aplicaciones (pp. 39-56). Universidad de Concepción: Concepción.

Bowker, J. y R. Trapp. (1992). Personal and ideational dimensions of good and poor arguments in human interaction. En F. van Eemeren y R. Grootendorst (eds.), Argumentation illuminated (pp. 220-230). Amsterdam: Sic Sat.

Dessalles, J-L.(2007). Why We Talk. The Evolutionary Origins of Language. New York: Oxford University Press. 
Dessalles, J-L. (2011). Reasoning as a lie detection device. Behavioral and Brain Sciences 34 (2), 76-77.

Ducrot, O. (2000). La elección de las descripciones en semántica argumentativa léxica. Discurso y Sociedad 2 (4): 33-44.

Ducrot, O. (2004). Sentido y argumentación. En Arnoux, E. \& M. M. García Negroni (eds.), Homenaje a Oswald Ducrot (pp. 359-370). Buenos Aires: Eudeba.

Ducrot, O. y M. Carel. (2006). La semántica argumentativa. Una introducción a la teoría de los bloques semánticos. Buenos Aires: Colihue.

Eemeren, F. van y Grootendorst, R. (2002). Argumentación, Comunicación, y Falacias. Una Perspectiva Pragma-dialéctica. Santiago: Ediciones Universidad Católica.

Eemeren, F. van y Grootendorst, R. (2004). A Systematic Theory of Argumentation. The pragma-dialectical approach. Cambridge: Cambridge University Press.

Eemeren, F., van. (2010). Strategic Maneuvering in Argumentative Discourse.Extending the Pragma-dialectical Theory of Argumentation. Amsterdam: John Benjamins.

Eemeren, van F., Garssen, B. y B. Meuffels. 2009. Fallacies and Judgments of Reasonableness. Empirical Research concerning the pragma-dialectical discussion rules. New York: Springer.

Evans, J. (2009). How many dual-process theories do we need? One, two, or many?En J. Evans y K. Frankish (Eds.),In Two Minds. Dual Processes and Beyond (pp. 3354), New York: Oxford University Press.

Evans, J. (2010). Thinking Twice. Two Minds in one brain. New York: Oxford University Press.

Evans, J. (2011). Reasoning is for thinking, not just for arguing. Behavioral and Brain Sciences 34 (2), 77-78.

Evans, J. y Frankish, K. (2009). In Two Minds. Dual Processes and Beyond. New York: Oxford University Press. 
Fletcher, L. y P. Carruthers (2012). Metacognition and Reasoning.Philosophical Transactions. The Royal Society of Biology 367: 1366-1378.

Frankish, K. (2009). Systems and levels: Dual-system theories and the personalsubpersonal distinction. En J. Evans y K. Frankish (Eds.), In Two Minds. Dual Processes and Beyond (pp. 89-108), New York: Oxford University Press.

Gigerenzer, G. (2008). Rationality for Mortals. How People cope with Uncertainty. New York: Oxford University Press.

Goffman, E. (1959). The presentation of self in everyday life. Woodstock, NY: Overlook Press.

Goffman, E. (1967). Interaction ritual: Essays in face-to-face behavior. Chicago: Aldine.

Goffman, E. (1969). Strategic interaction. Philadelphia: University of Pennsylvania Press.

Goodwin, J. (2007). Argument has No function. Informal Logic 27 (1), 69-90.

Hample, D. (2005). Arguing: Exchanging Reasons Face to Face.Mahwah, NJ: Erlbaum.

Hample, D., Warner, B. y Young, D. (2009). Framing and Editing Interpersonal Arguments. Argumentation23:21-37

Hample, D., Han, B. y Payne, D. (2010). The Aggressiveness of Playful Arguments. Argumentation 24: 405-421.

Jelvez, L. (2008). Esquemas argumentativos en textos escritos: un estudio descriptivo en alumnos de tercero medio de dos establecimientos de Valparaíso. Cyber Humanitatis 45: 1-15.

Johnson-Laird, P. (2008). How We Reason. New York: Oxford University Press.

Johnson, R. (2000). Manifest Rationality. A Pragmatic Theory of Argument. New Jersey: Lawrence Erlbaum Associates, Inc. 
Johnson, R. y A. Blair.(1977). Logical self-defense. Toronto: McGraw-Hill Ryerson.

Kahneman, D. (2011). Thinking, fast and slow. London: Allen Lane.

Leitão, S. (2000).The potential of argument in knowledge building. Human Development 6: 332-360.

Leitão, S. (2008). La dimensión epistémica de la argumentación. En E. Kronmüller y C. Cornejo (Eds.), Ciencias de la Mente: Aproximaciones desde Latinoamérica. Santiago: J.C. Sáez Editor.

Manktelow, K., Over, D. y Elqayam, Sh. (Eds.) (2011). The Science of Reason. A Fetschrift for Jonathan St. B. T. Evans.Hove: PsychologyPress.

Marinkovich, J. (2007). La interacción argumentativa en el aula: fases de la argumentación y estrategias de cortesía verbal. En C. Santibáñez y B.Riffo (Eds.), Estudios en Argumentación y Retórica. Teorías contemporáneas y aplicaciones (pp. 227-252.). Concepción: Editorial Universidad de Concepción.

Mercier, H. (2011a). When experts argue: explaining the best and the worst of reasoning. Argumentation, 23(3): 313-327.

Mercier, H. (2011b). On the universality of argumentative reasoning. Journal of Cognition and Culture, 11(1-2): 85-113.

Mercier, H. (2011c). Reasoning serves argumentation in children. Cognitive Development, 26(3): 177-191.

Mercier, H. (2011d). What good is moral reasoning? Mind \& Society 10 (2): 131-148.

Mercier, H. (2012). Looking for Arguments. Argumentation 26(3): 305-329.

Mercier, H. y Landemore, H. (2012). Reasoning is for arguing: Understanding the successes and failures of deliberation. Political Psychology 33: 243-258. 
Mercier, H. y Sperber, D. (2009) Intuitive and reflective inferences. En J. Evans y K. Frankish (eds.), In Two Minds: Dual Processes and Beyond. Oxford: Oxford University Press, 149-170.

Mercier, H. y Sperber, D. (2011a).Why do human reason? Arguments for an argumentative theory. Behavioral and Brain Sciences 34(02): 57-74.

Mercier, H. y Sperber, D. (2011b) “Argumentation: its adaptiveness and efficacy. Response to commentaries on "Why do humans reason?" Behavioral and Brain Sciences 34(2): 94-111.

Meza, P. (2009). Las interacciones argumentativas orales en la sala de clases: un análisis dialéctico y retórico. Tesis de Grado, PUCV.

Oaksford, M. y Chater, N. (2007).Bayesian rationality: The Probabilistic approach to human reasoning. Oxford: Oxford UniversityPress.

Padilla, C. y López, E. (2011). Grados de complejidad argumentativa en escritos de estudiantes universitarios de humanidad. Revista Praxis, 13 (20): 61-90.

Paglieri F. y Castelfranchi, C. (2010). Why arguing? Towards a costs-benefits analysis of argumentation. Argument \& Computation 1: 71 - 91.

Patterson, S. (2011). Functionalism, Normativity and the Concept of Argumentation.Informal Logic 31 (1), 1-26.

Ricco, R. y Sierra, A. (2011). Individual Differences in the Interpretation of Commitment in Argumentation. Argumentation 25: 37-61.

Santibáñez, C. (2012). Mercier and Sperber's Argumentative Theory of Reasoning.From the Psychology of Reasoning to Argumentation Studies. Informal Logic 32 (1): 132-159.

Schreier, M., N. Groeben y U. Christmann (1995). That's not fair! Argumentational integrity as an ethics of argumentative communication. Argumentation 9: 267289. 
Sperber, D. (2001). An evolutionary perspective on testimony and argumentation. Philosophical Topics 29: 401-413.

Sperber, D. et al. (2010). Epistemic Vigilance.Mind and Language 25 (4): 359-393.

Sperber, D., Mercier, H. (2012). Reasoning as a social competence. En H. Landemorey J. Elster (Eds.), Collective Wisdom: Principles and Mechanisms. Cambridge: Cambridge University Press, 368-392.

Stanovich, K. (2011). Rationality and Reflective Mind. New York: Oxford University Press.

Stanovich, K. y Toplak, M. (2012). Defining features versus Incidental Correlates of Type 1 and Type 2 processing. Mind and Society 11(1): 3-13.

Tindale, C. (2004). Rhetorical Argumentation. New York: Sage.

Todd, P., Gigerenzer, G., y el GRUPO ABC.(2012). Ecological Rationality. Intelligence in the World. New York: Oxford University Press.

Toulmin, S. (1958).The uses of Argument. Cambridge: Cambridge University Press.

Toulmin, S., R. Rieke y A. Janik.(1978). An introduction to reasoning. New York: Macmillan Publishing Co., Inc.

Walton, D. (1989). Informal Logic. Cambridge: Cambridge University Press.

Walton, D. (1992). Plausible Argument in Everyday Conversation. New York: State University of New York Press.

Walton, D. (1997). Appeal to pity. Argumentum ad misericordiam. New York: State University of New York.

Walton, D. (2004). Abductive reasoning. Tuscaloosa: The University of Alabama Press.

Walton, D. (2007). Media Argumentation.Dialectic, Persuasion, and Rhetoric. Cambridge: Cambridge University Press. 
Walton, D., Reed, C. y Macagno, F. (2008).Argumentation Schemes. New York: Cambridge University Press.

Zenker, F. (2011).Why Study the Overlap Between "Ought” and "Is" Anyways? On Empirically Investigating the Conventional Validity of the Pragma-Dialectical Discussion Rules. In: Eemeren, F.H. van, Garssen, B., Godden, D., and Mitchell, G. (eds). Proceedings of the 7th International Conference of the International Society for the Study of Argumentation (ISSA).SitSac: Amsterdam, 2083-2091.

Anexo

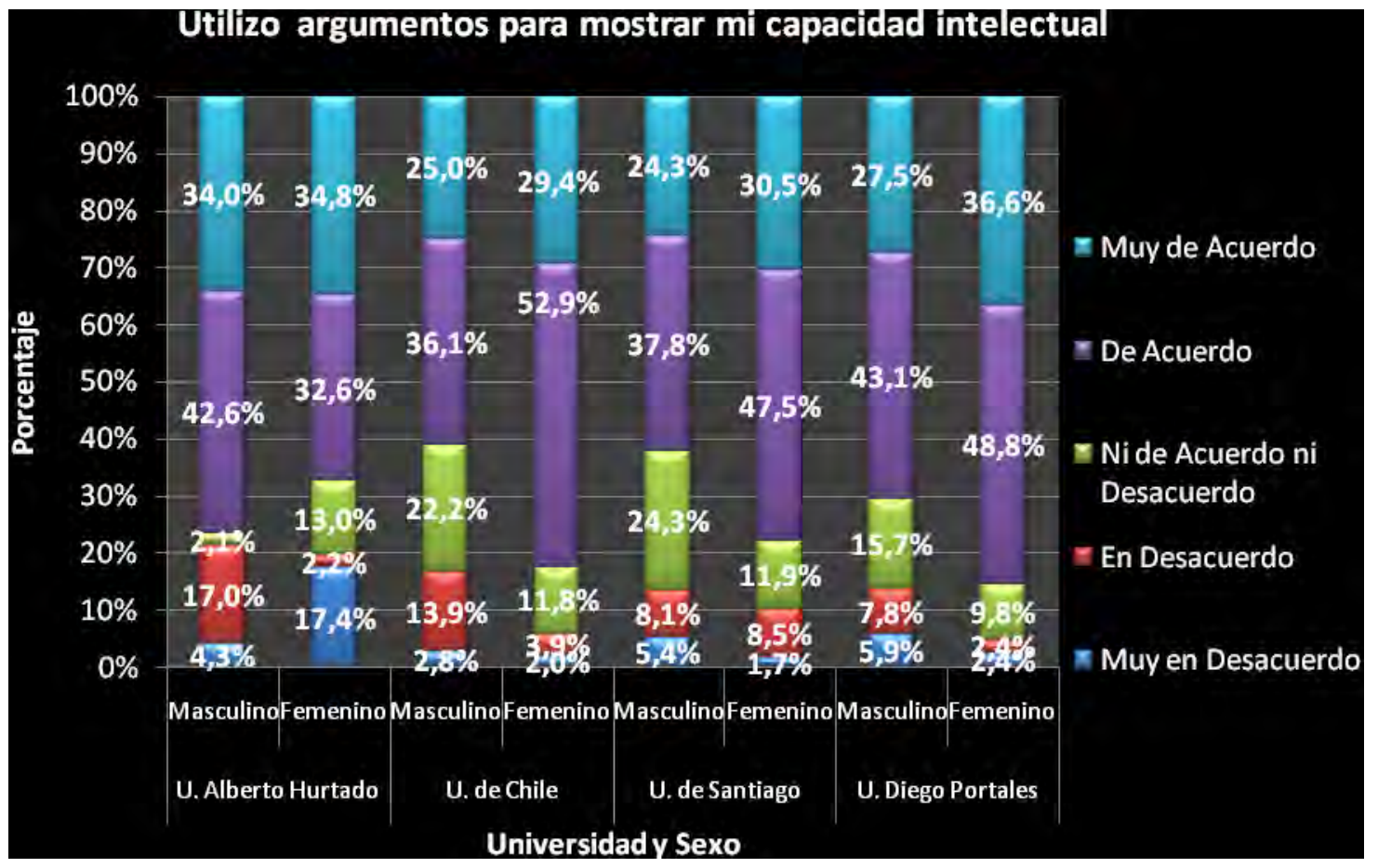

Gráfico 5. Fuente: Investigación 2013VFC. 


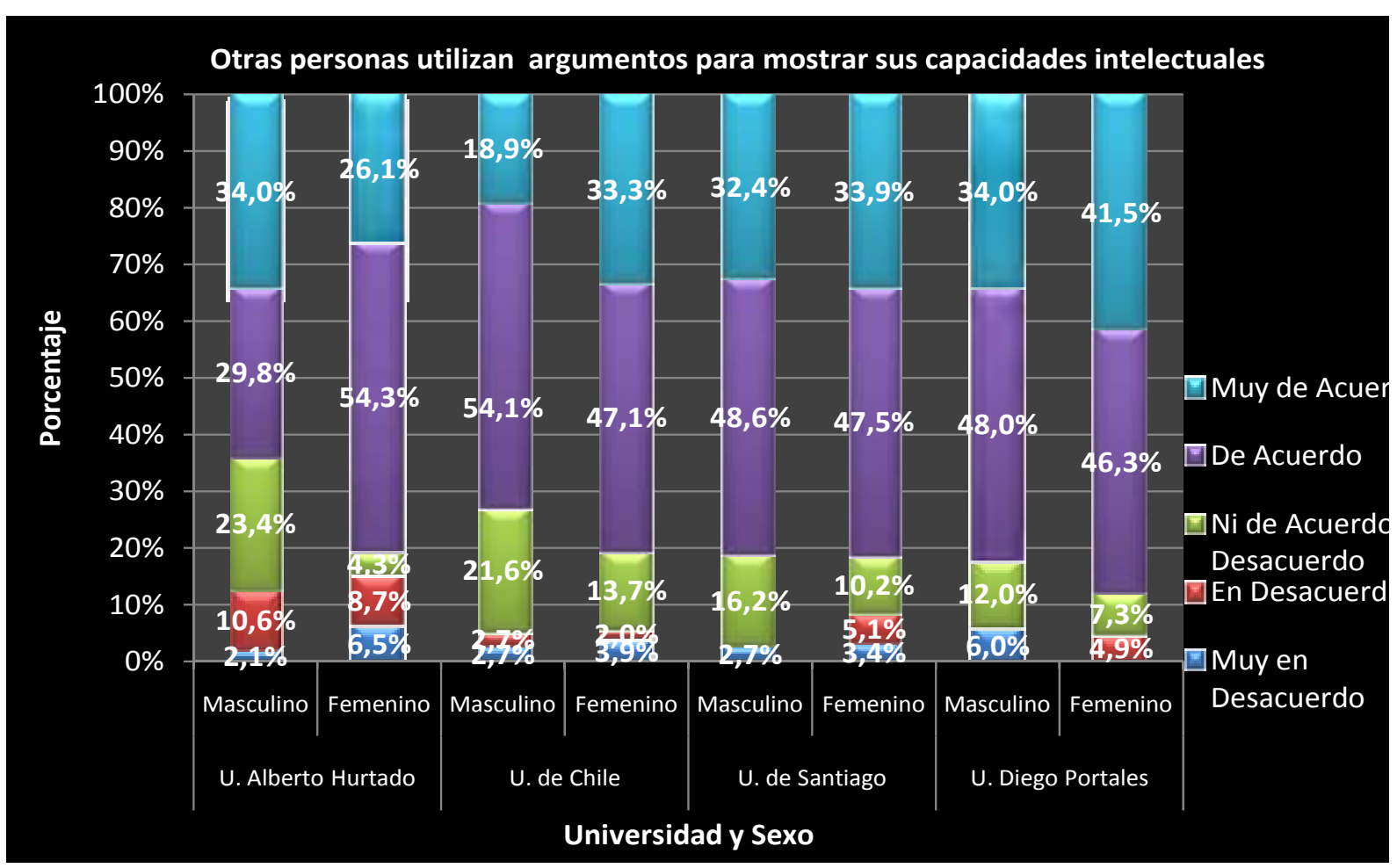

Gráfico 6. Fuente: Investigación 2013VFC.

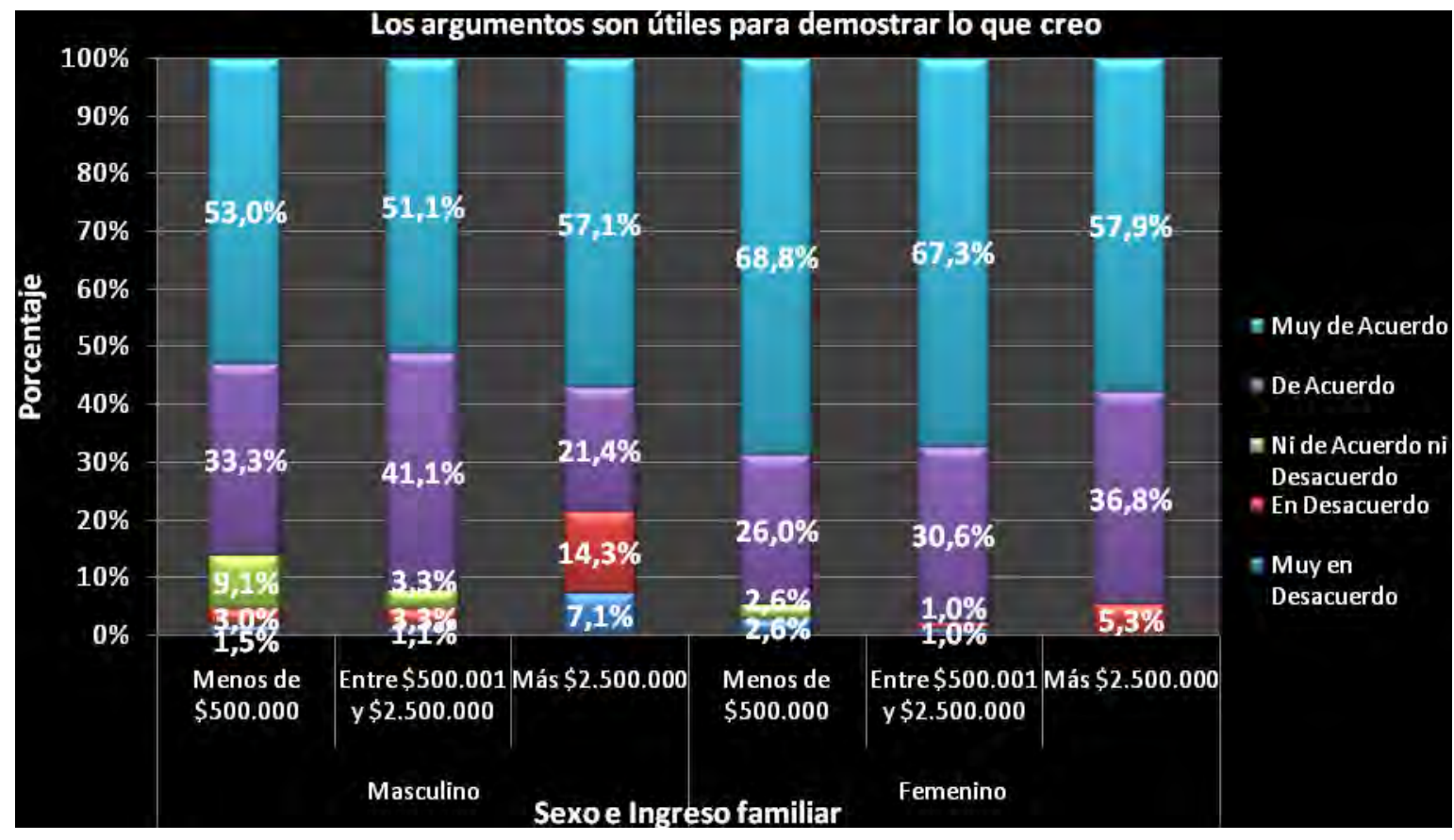

Gráfico 7. Fuente: Investigación2013 VFC. 


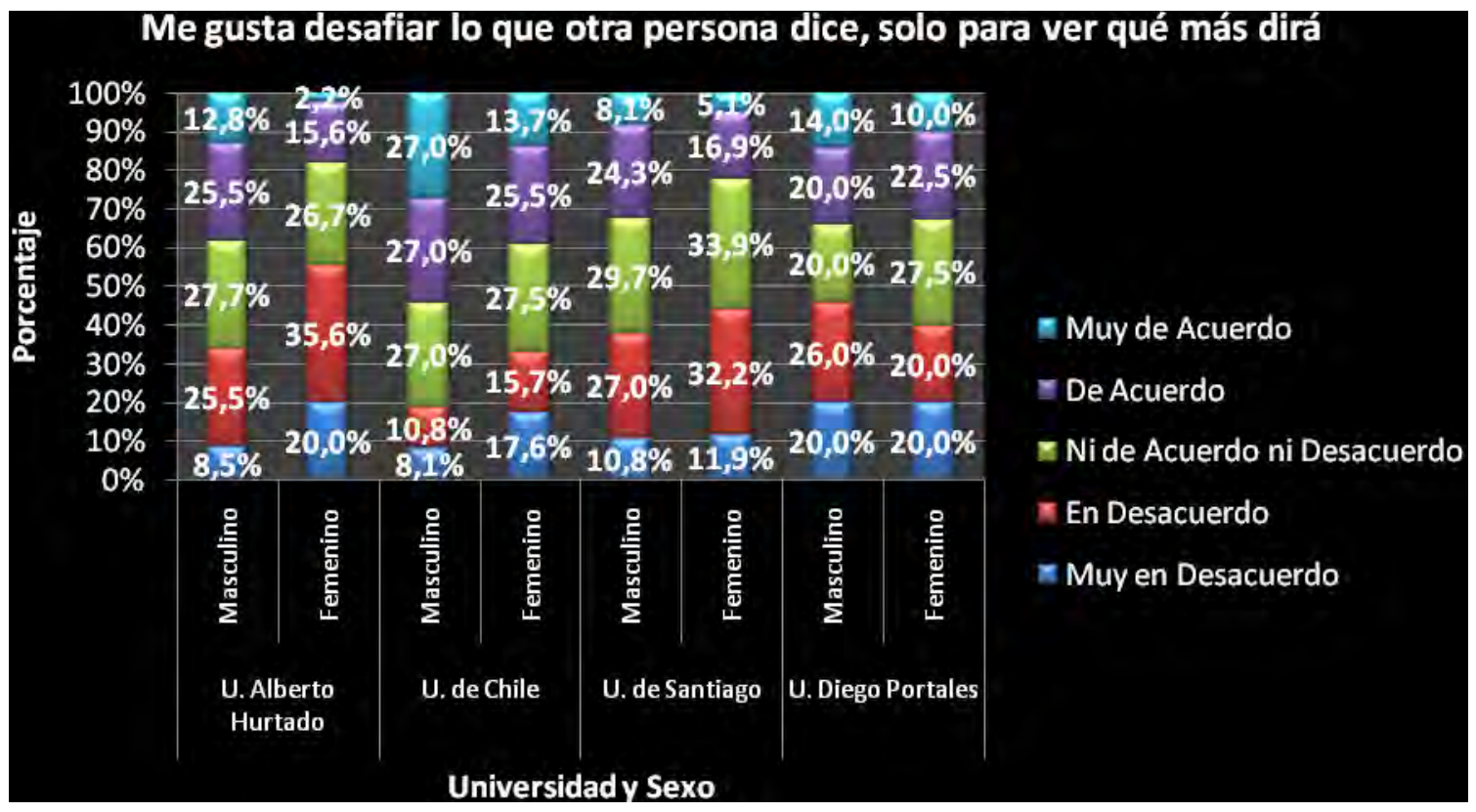

Gráfico 8. Fuente: Investigación 2013VFC.

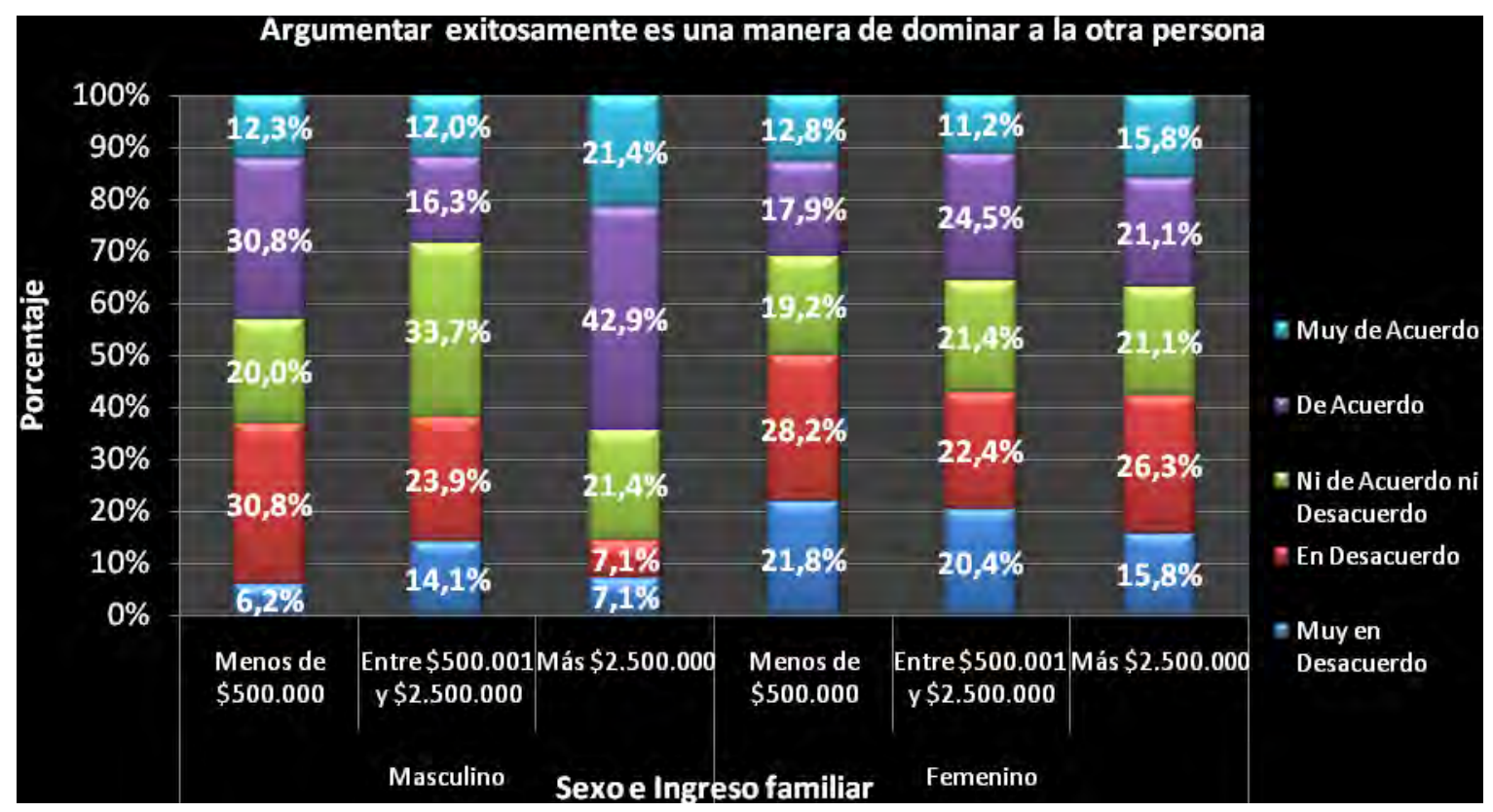

Gráfico 9. Fuente: Investigación 2013VFC. 


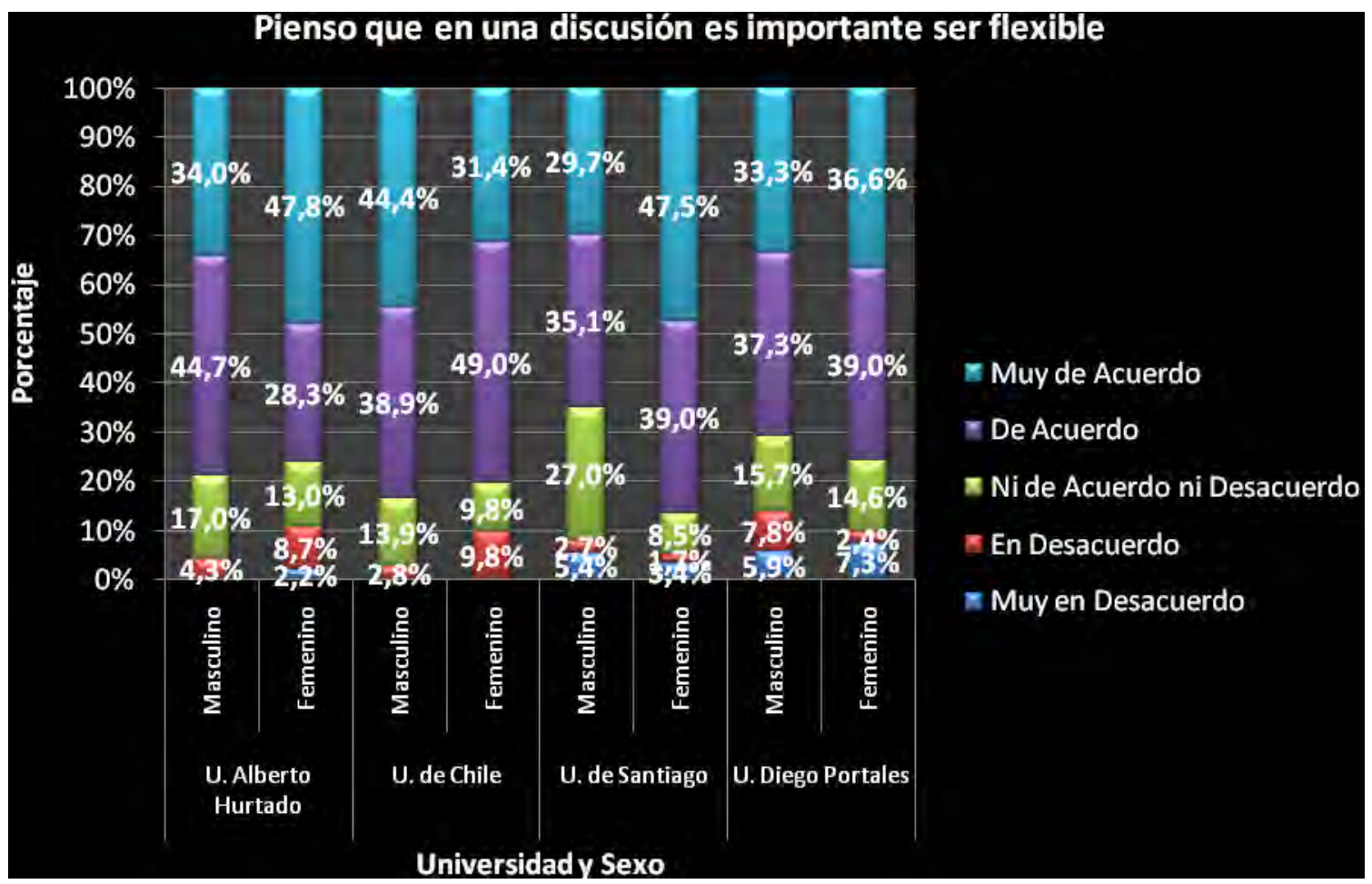

Gráfico 10. Fuente: Investigación 2013 VFC.

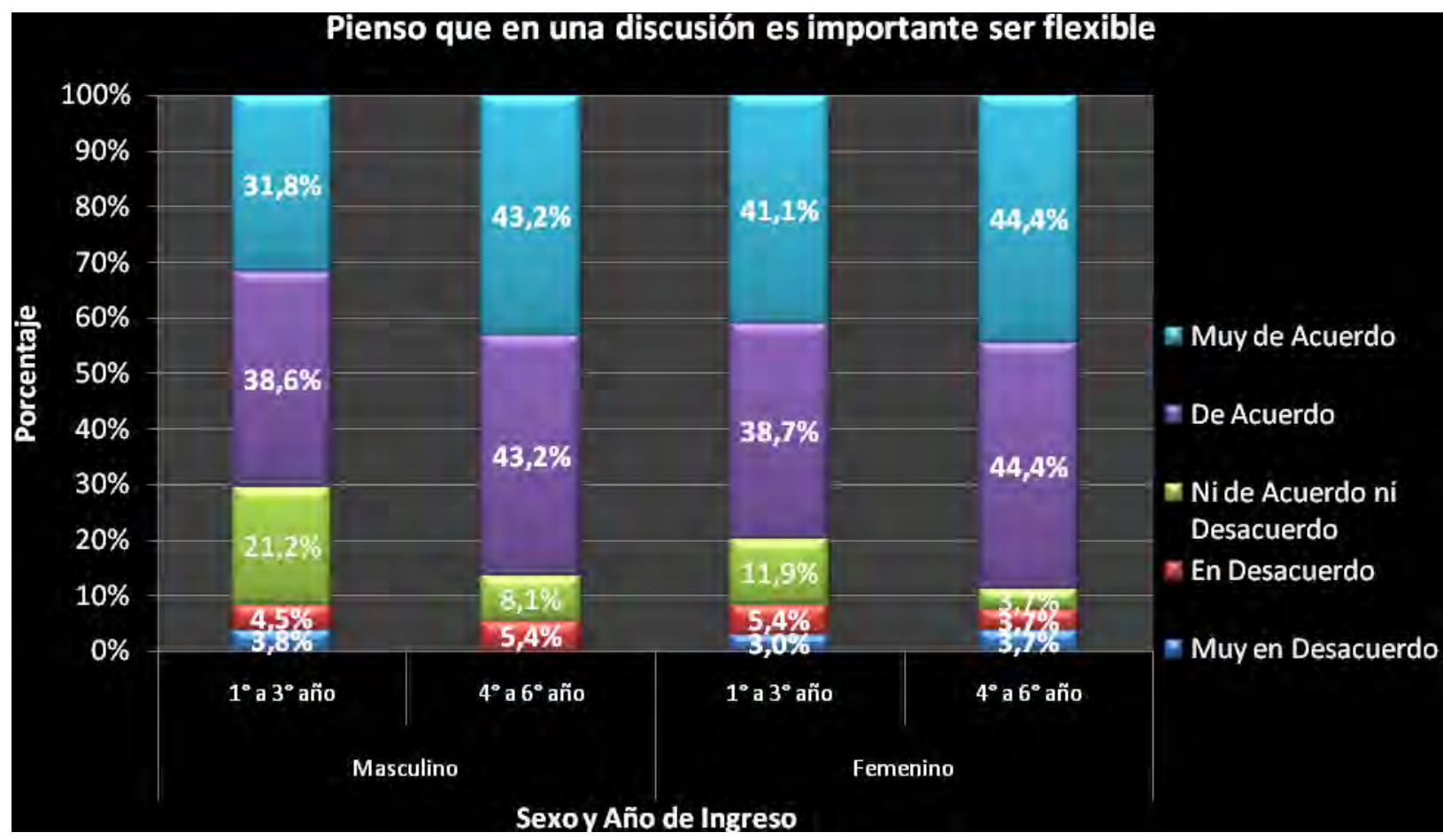

Gráfico 11. Fuente: Investigación 2013VFC. 


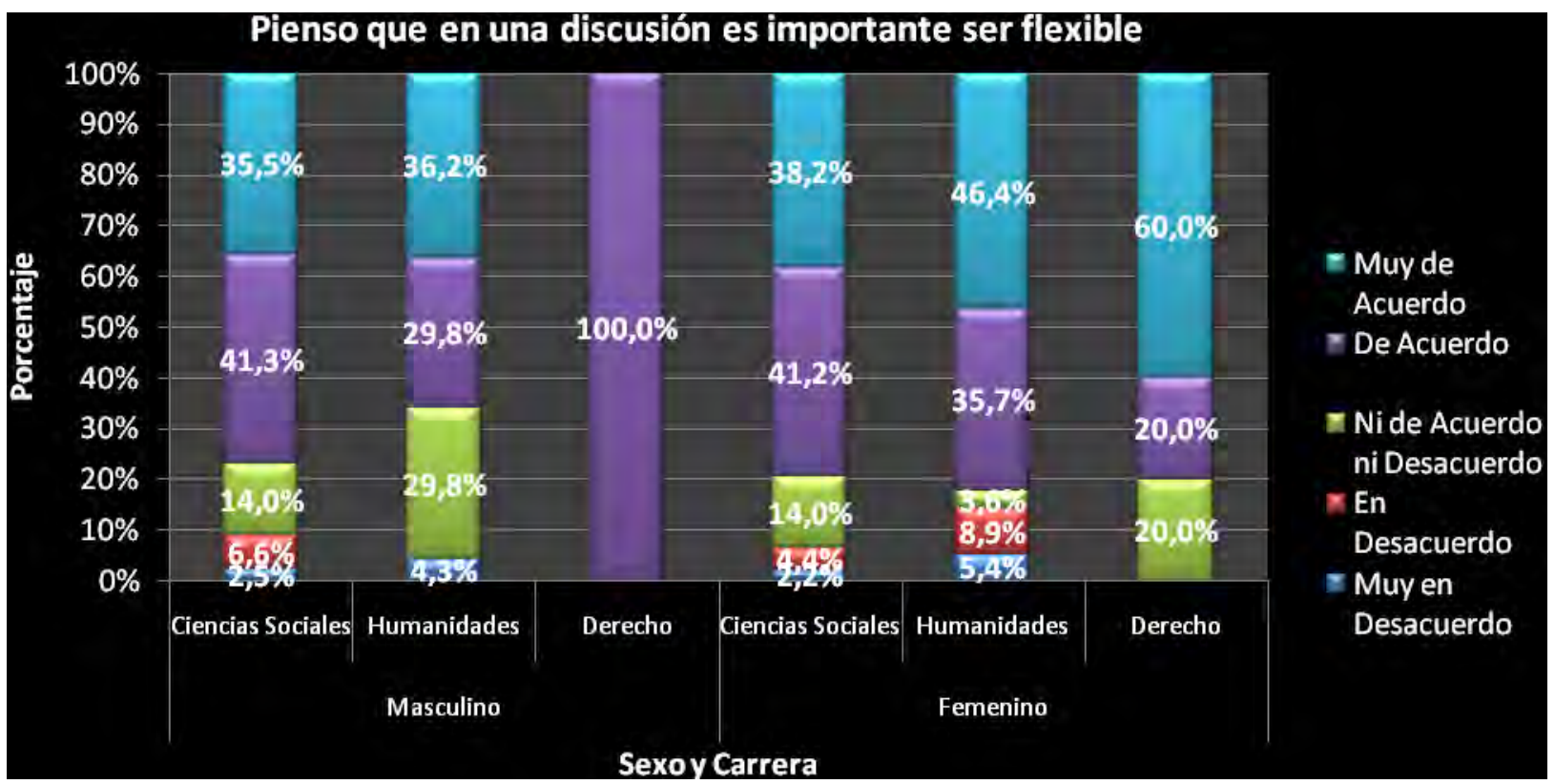

Gráfico 12. Fuente: Investigación 2013VFC.

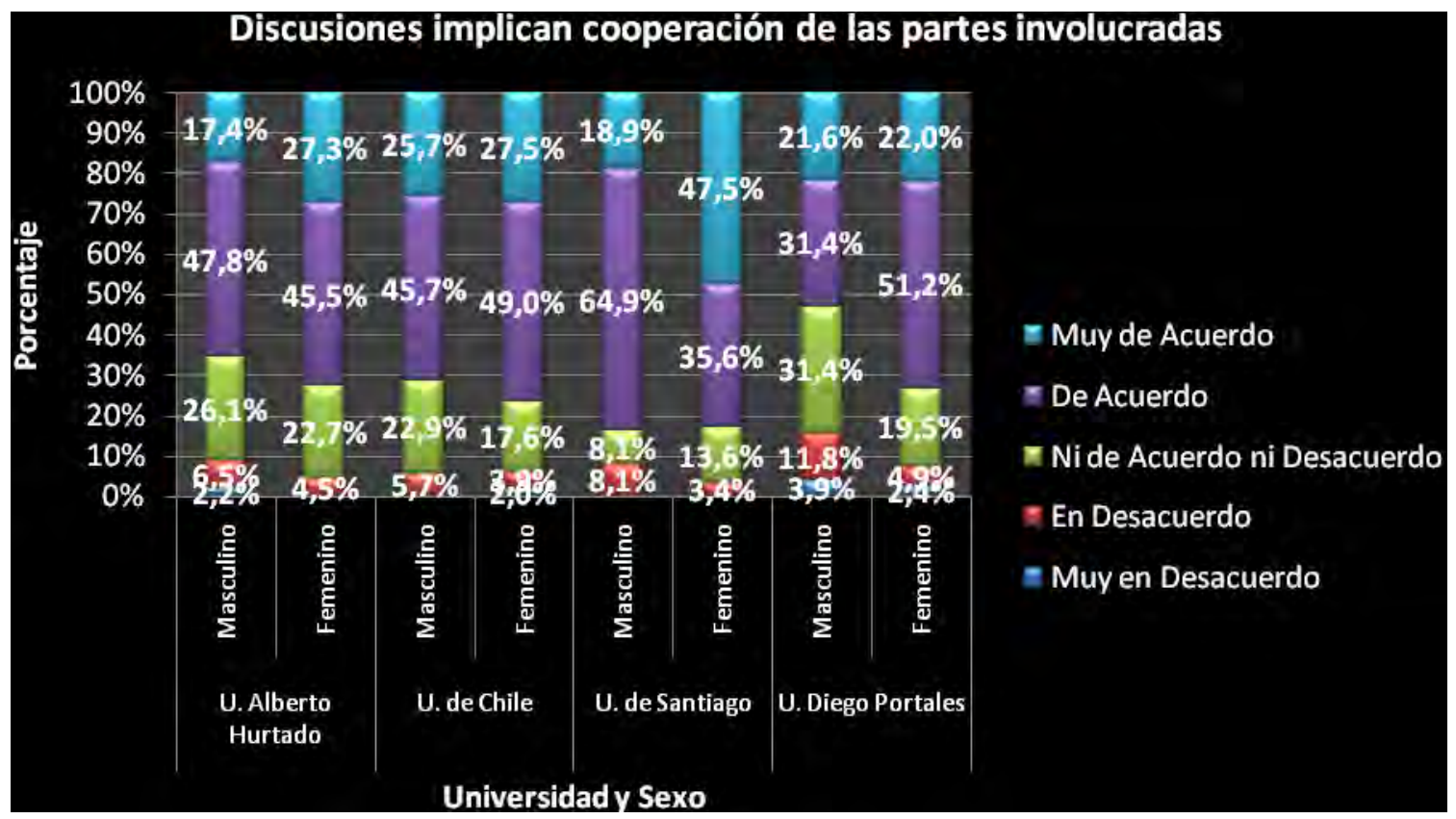

Gráfico 13. Fuente: Investigación 2013VFC. 


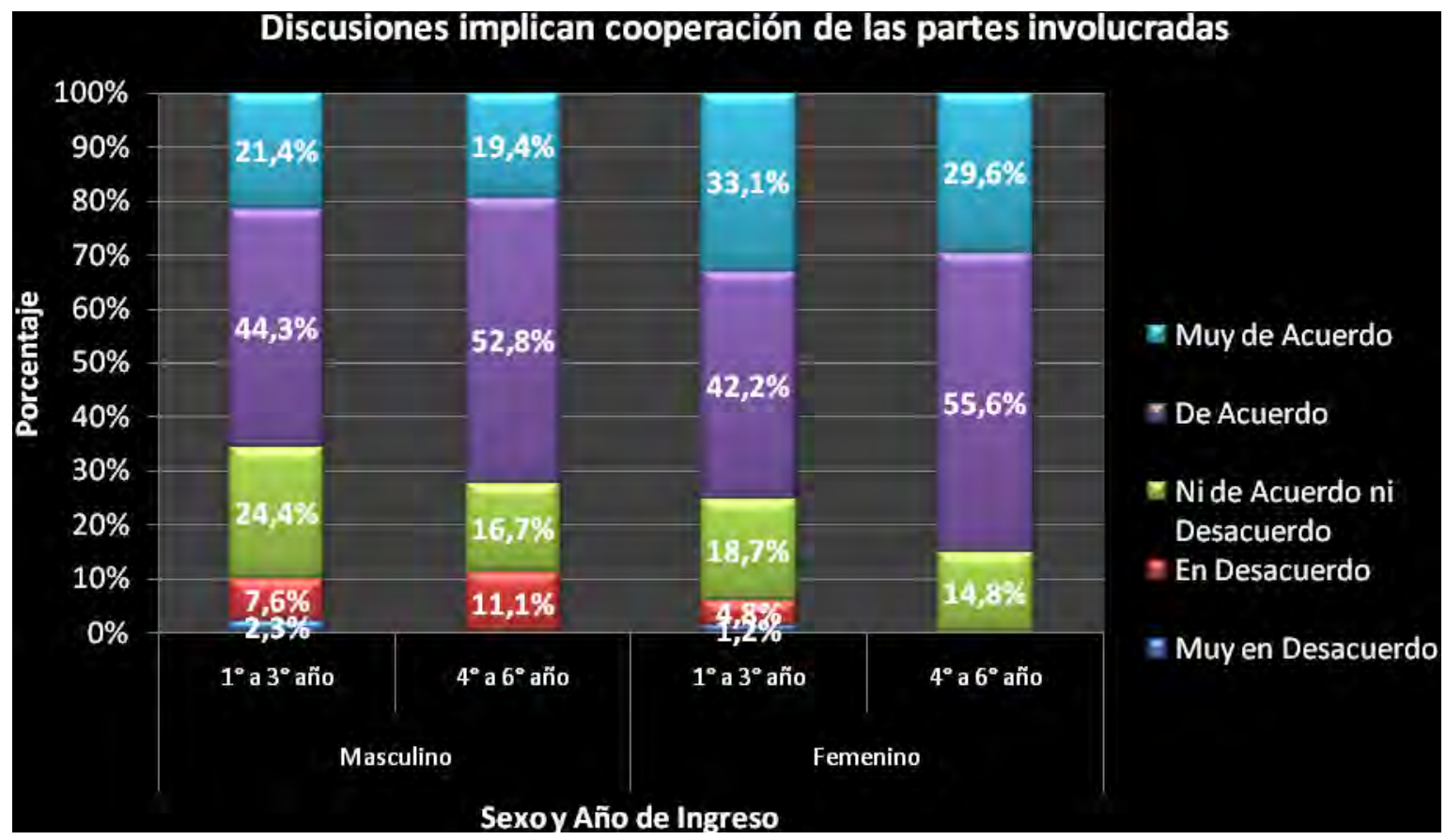

Gráfico 14. Fuente: Investigación 2013VFC.

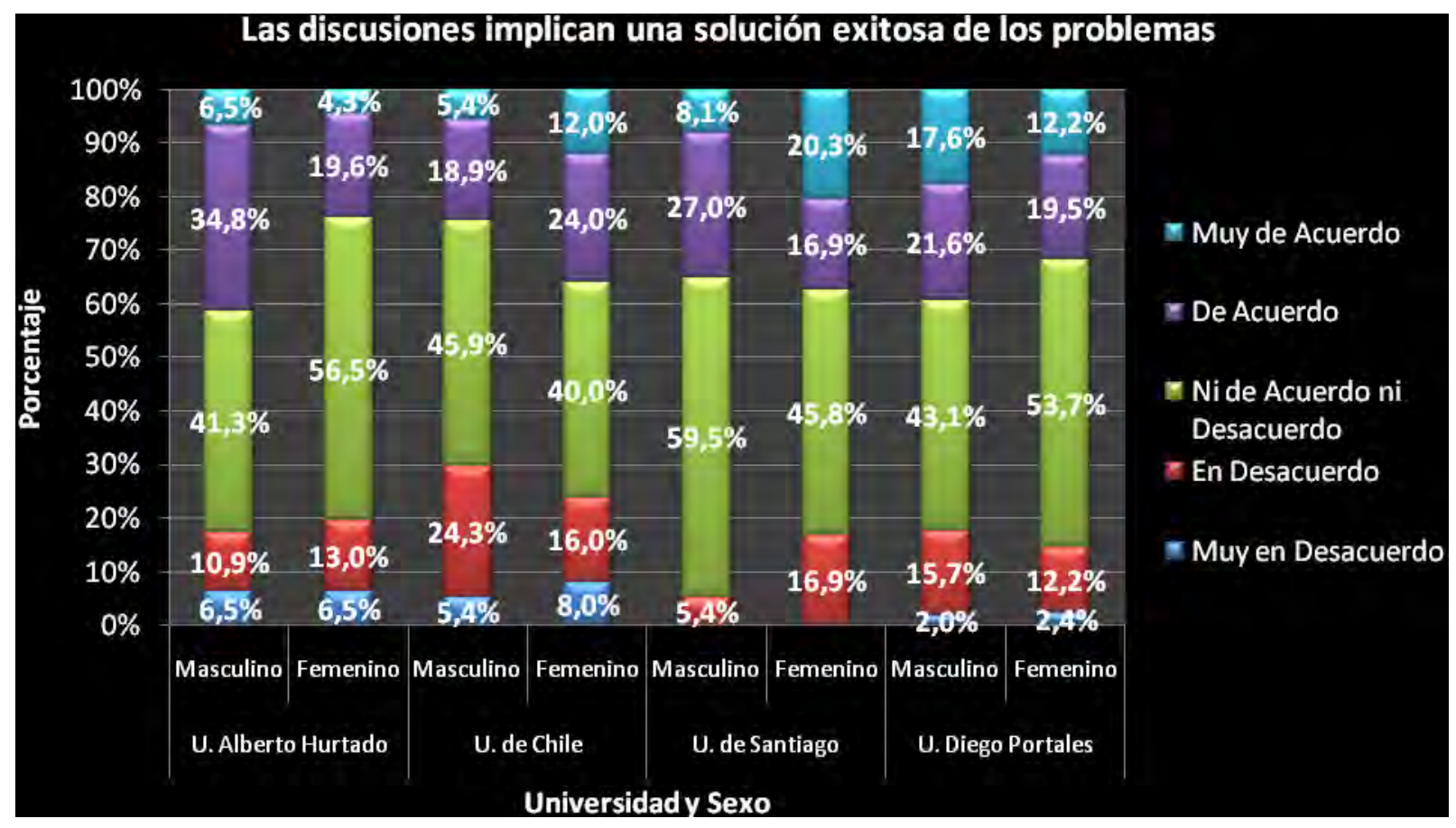

Gráfico 15. Fuente: Investigación 2013VFC. 


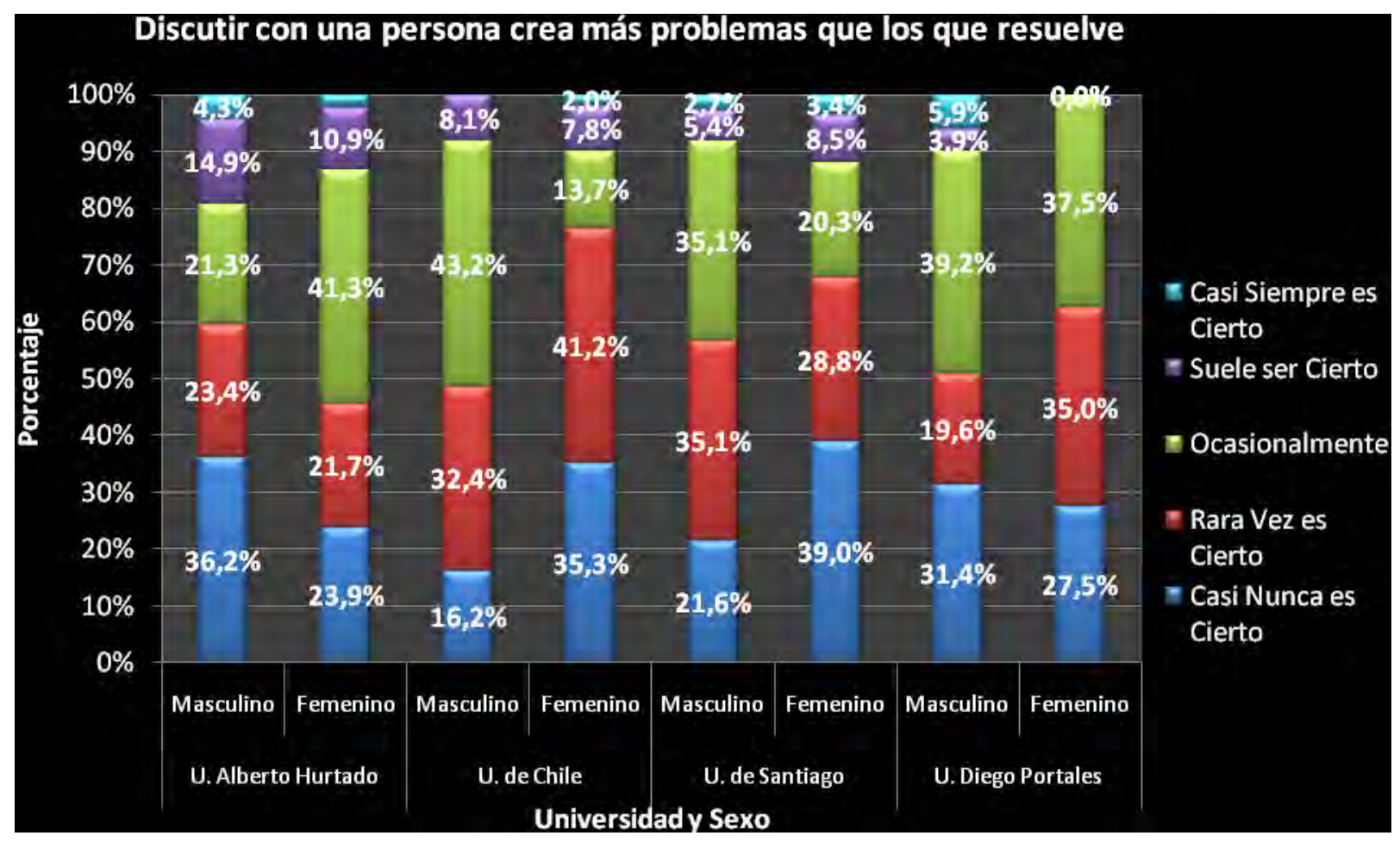

Gráfico 16. Fuente: Investigación 2013VFC.

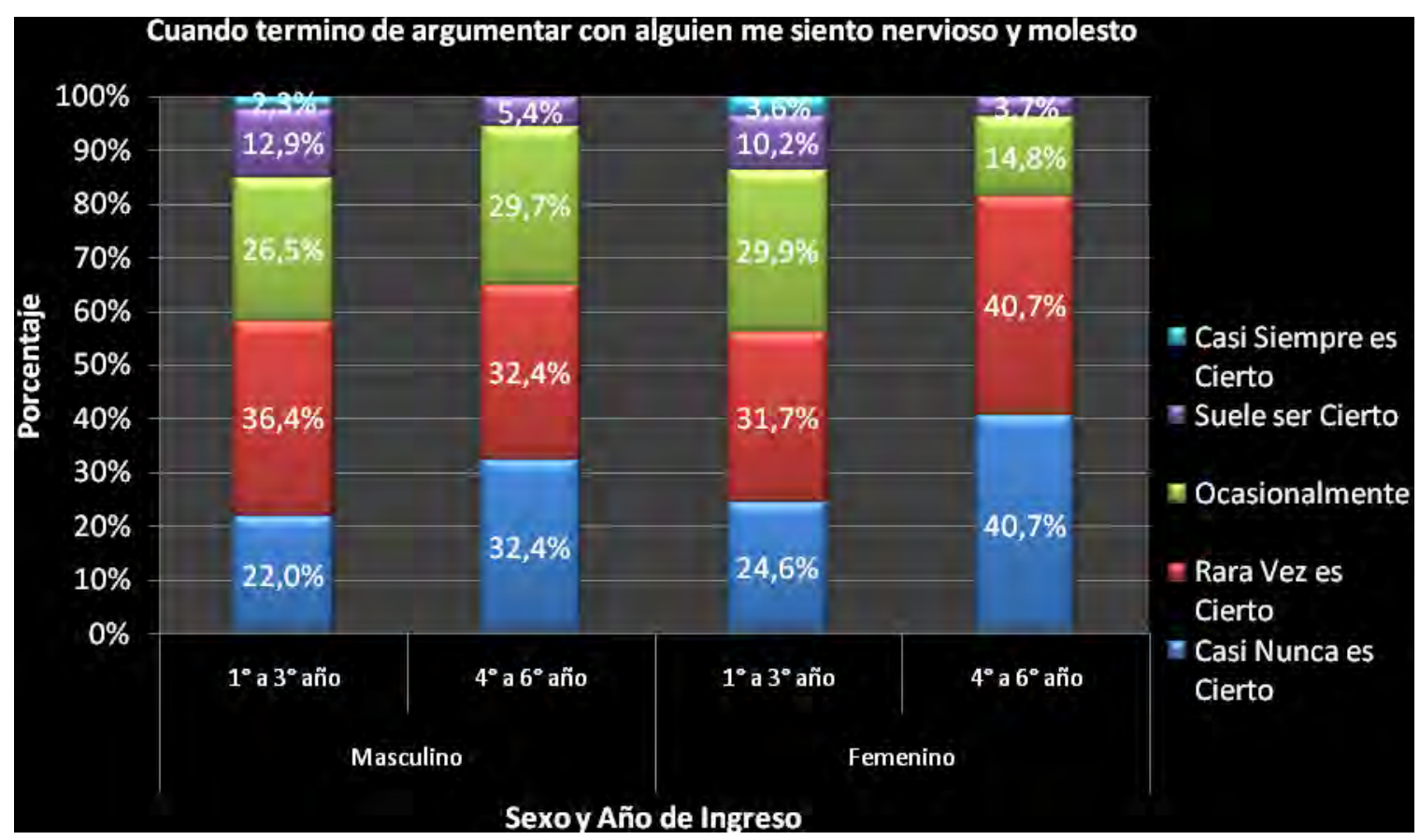

Gráfico 17. Fuente: Investigación 2013VFC. 


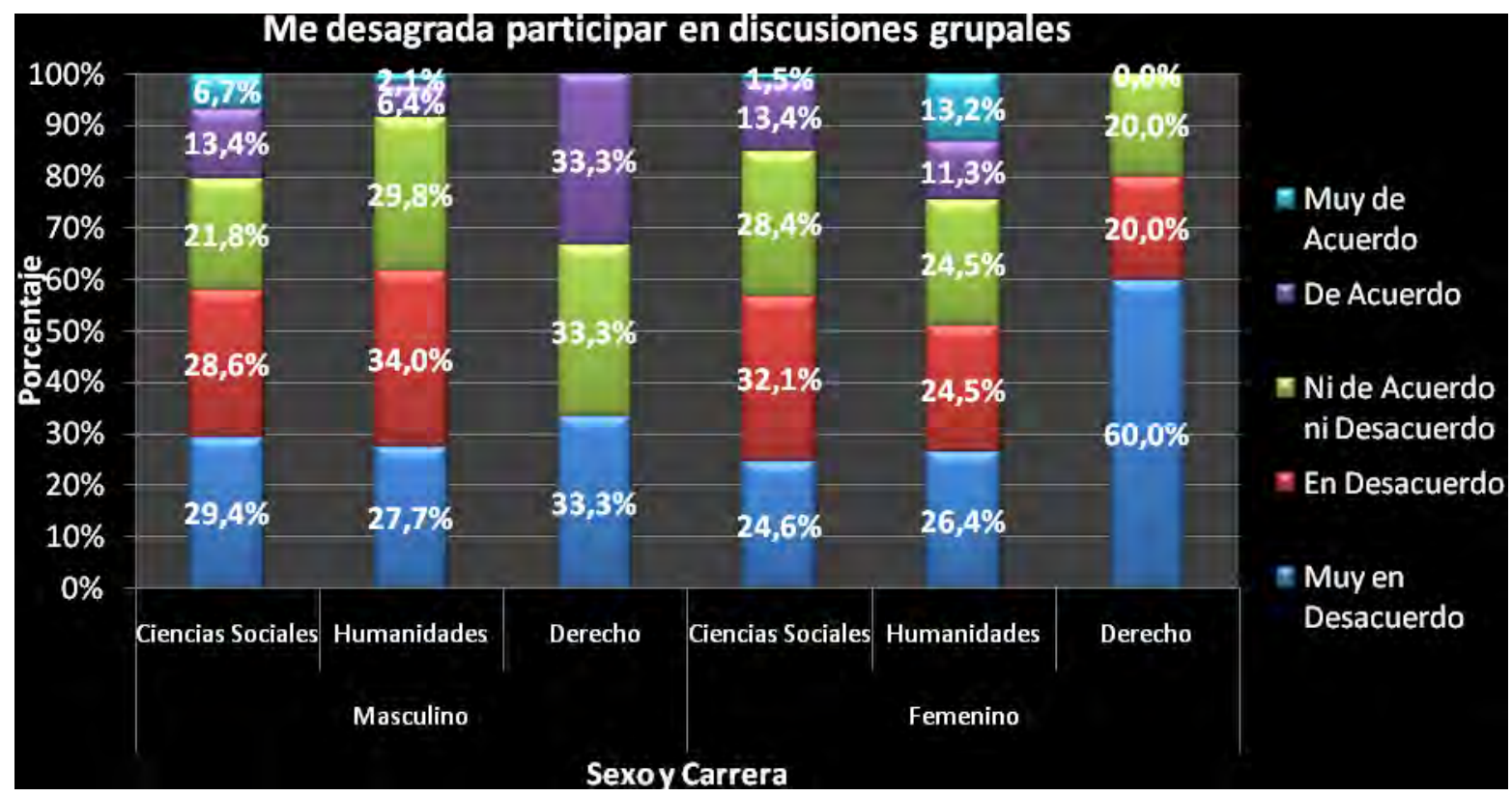

Gráfico 18. Fuente: Investigación2013 VFC.

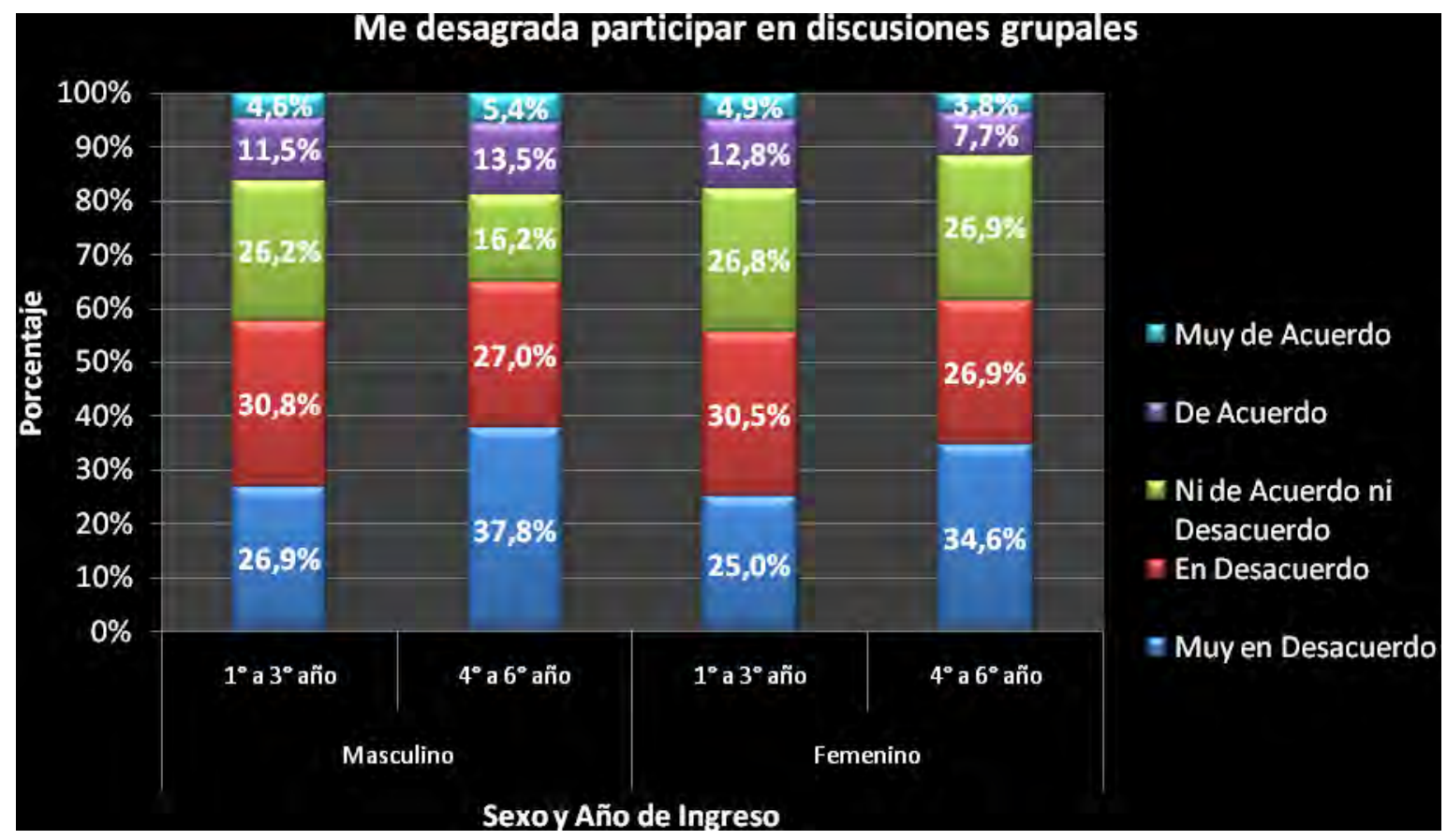

Gráfico 19. Fuente: Investigación 2013 VFC.

Recibido: 1 marzo 2013

Aceptado: 26 mayo 2014

Revisado: 29 mayo 2014

Publicado: 31 mayo 2014

Actualizado: 2 junio 2014 